\title{
Whatever it takes: rivalry and unethical behavior
}

\section{Article}

Accepted Version

Kilduff, G. J., Galinsky, A. D., Gallo, E. and Reade, J. J. (2016) Whatever it takes: rivalry and unethical behavior. Academy of Management Journal, 59 (5). pp. 1508-1534. ISSN 1948-0989 doi: https://doi.org/10.5465/amj.2014.0545 Available at https://centaur.reading.ac.uk/47395/

It is advisable to refer to the publisher's version if you intend to cite from the work. See Guidance on citing.

To link to this article DOI: http://dx.doi.org/10.5465/amj.2014.0545

Publisher: Academy of Management

All outputs in CentAUR are protected by Intellectual Property Rights law, including copyright law. Copyright and IPR is retained by the creators or other copyright holders. Terms and conditions for use of this material are defined in the End User Agreement.

\section{www.reading.ac.uk/centaur}

\section{CentAUR}

Central Archive at the University of Reading

Reading's research outputs online 


\title{
Whatever It Takes to Win: Rivalry Increases Unethical Behavior
}

\author{
Gavin J. Kilduff \\ New York University \\ gkilduff@ stern.nyu.edu \\ 814-441-1510
}

Adam D. Galinsky

Columbia University

adamgalinsky@columbia.edu

773-495-2999

Edoardo Gallo

University of Cambridge and Queens' College

edo@econ.cam.ac.uk

+44 (0) 1223335286

\author{
J. James Reade \\ University of Reading \\ j.j.reade@ reading.ac.uk \\ +44 (0) 1183785062
}




\title{
Whatever it takes to win: Rivalry increases unethical behavior
}

\begin{abstract}
This research investigates the link between rivalry and unethical behavior. We propose that people will be more likely to engage in unethical behavior when competing against their rivals than when competing against non-rival competitors. Across an archival study and a series of experiments, we found that rivalry was associated with increased unsportsmanlike behavior, use of deception, and willingness to employ unethical negotiation tactics. We also explored the psychological underpinnings of rivalry, which help to illuminate how rivalry differs from general competition and why it increases unethical behavior. The data reveal a serial mediation pathway whereby rivalry heightens the psychological stakes of competition (by increasing actors' contingency of self-worth and status concerns), which leads them to adopt a stronger performance approach orientation, which then increases unethical behavior. These findings highlight the importance of rivalry as a widespread, powerful, yet largely unstudied phenomenon with significant organizational implications. They also help to inform when and why unethical behavior occurs within organizations, and demonstrate that the effects of competition are dependent upon relationships and prior interactions between actors.
\end{abstract}

Keywords: Rivalry, competition, unethical behavior, ethics 
"I want them on their knees. Begging for mercy. Pleading for their lives. Confessing every sin. Kill! Kill! Kill!”

Oracle CEO Larry Ellison, “speaking” to fellow executives about Ingres, his company’s primary rival in the early 1980 s. $^{1}$

A wide range of anecdotal evidence suggests that certain competitors - rivals - can push us to pursue victory with a fervency that goes beyond the bounds of normal, and often ethical, competitive behavior. In athletics, few can forget the brutal physical attack perpetrated by Tonya Harding's ex-husband against her rival Nancy Kerrigan in the 1994 Winter Olympics. In the U.S. military, inter-service rivalries (e.g., The Air Force vs. The Navy) have been linked to unethical practices such as fudging performance data (Ash, 2001). In business, British Airways’ executives admitted in a 1993 libel suit that they had engaged in a "dirty tricks" campaign against rival Virgin Atlantic, which included stealing Virgin's confidential data, calling Virgin's customers to tell them their flights had been cancelled, and circulating rumors that Virgin CEO Richard Branson had contracted HIV (Gregory, 1994).

Such examples suggest that the experience of rivalry goes beyond that of everyday competition. However, researchers have generally treated rivalry and competition as one and the same, leaving us largely uninformed about this prevalent and powerful phenomenon. We believe that distinguishing rivalry and competition is conceptually important, and critical for understanding and predicting behavior within competitive environments and organizations. We build upon recent research by conceptualizing rivalry as a subset of competition that is uniquely relational, and then compare the effects of rivalry and non-rival competition on unethical

${ }^{1}$ White, 2001, pp. 373-374 
behavior. Across four studies, we find that rivalry makes people more likely to do "whatever it takes" to get ahead, independent of the tangible stakes of competition. We also examine the psychology of rivalry and the mechanisms that explain its effects on unethical behavior. We find that competition against rivals invokes greater psychological stakes, in the form of increased contingency of self-worth (e.g., Crocker \& Wolfe, 2001) and increased status concerns (Blader \& Chen, 2011), compared to non-rival competitors. These increased psychological stakes in turn lead people to adopt a stronger performance approach orientation against rivals (Dweck \& Legget, 1988), which leads to greater unethical behavior.

We seek to make several theoretical contributions with this research. First, we extend existing work on rivalry, which suggests that it fosters greater motivation and effort (Kilduff, 2014; Kilduff, Elfenbein, \& Staw, 2010; Ku et al., 2005; Malhotra, 2010), by exploring its “dark side." Second, as described above, we offer new insights into the psychology of rivalry and how it differs from non-rival competition. Third, we extend scholars' understanding of the roots of unethical behavior and organizational misconduct by identifying rivalry as a previously unexplored antecedent of such behavior. In doing so, we also shed light on the conditions under which competition is more or less likely to corrupt. Fourth, our research broadly extends prevailing theoretical models of both competition and unethical behavior by depicting these phenomena as inherently relational - dependent upon existing relationships and histories of interaction between actors. Research in both of these areas has focused on identifying the individual and situational drivers of behavior (e.g., Kish-Gephart, Harrison, \& Treviño, 2010); our work adds to a small but growing body of work showing that relational factors matter as well (e.g., Gino, Ayal, \& Ariely, 2009; Tesser, 1988), which suggests new avenues for research. 


\section{RIVALRY AND COMPETITION: THE CRITICAL ROLE OF PRIOR RELATIONSHIPS}

Competition is everywhere, in nature and modern civilization alike, and thus has long been a topic of interest to researchers across the social sciences. Prevailing theoretical models within management, economics, and psychology view competition in primarily structural terms as a situation in which the outcomes of actors are opposed to one another, i.e., actors are vying for the same scarce resources (e.g., Deutsch, 1949; Porter, 1980; Scherer \& Ross, 1990). For instance, competition between individuals has been experimentally created by offering rewards to the highest performer (e.g., Beersma, Hollenbeck, Humphrey, Moon, \& Conlon, 2003; Scott \& Cherrington, 1974) or by giving individuals the goal of outperforming each other (e.g., Deci, Betley, Kahle, Abrams, \& Porac, 1981; Tauer \& Harackiewicz, 1999). Similarly, competition between organizations has been measured by the extent to which firms operate in the same markets, vying for customers and market share (e.g., Chen, 1996; Greve, 1998).

Within these literatures, the word "rivalry" is generally used synonymously with competition; rivals are simply actors in competition with one another, whether at the individual (e.g., Wankel, 1972) or organizational levels (e.g., Katila \& Chen, 2008; Porter, 1980). However, in line with recent research (Kilduff, 2014; Kilduff et al., 2010), we believe that there is more to rivalry than just a state of opposing goals or contested resources. Equating rivalry with such 'structural' competition fails to capture the relational and historical factors that are essential to rivalry. Is the rivalry between Oxford and Cambridge University nothing more than a current state of conflicting goals? Why are Pete Sampras and Andre Agassi so fiercely competitive with one another more than a decade after any meaningful competition, even during matches staged purely for charity (http://www.aolnews.com/2010/03/13/agassi-sampras-feud- 
publicly-at-charity-event)? In these examples, there exists a relationship and history that extends beyond just a current state of conflict over tangible resources, which we believe may substantially affect behavioral responses to competition.

\section{CONCEPTUALIZATION OF RIVALRY}

We follow Kilduff et al. (2010) in conceptualizing rivalry as a relationship between a focal actor and a target actor that is characterized by the experience of heightened psychological stakes of competition by the focal actor when competing against the target actor. Thus, rivalry exists when the psychological stakes of competition are increased as a result of the existing relationship between competitors, independent of objective stakes or other structural or situational characteristics. Below, we discuss the factors that can lead to the development of rivalry, including repeated competition and closely-decided past contests; we also examine more precisely the nature of these proposed psychological stakes.

This conceptualization of rivalry can be seen as analogous to how one might conceptualize friendship, a relationship characterized by increasing liking and familiarity that typically emerges from factors such as repeated social interaction and similarity in interests. In both friendship and rivalry, the psychological significance of an interaction is intensified by the existing relationship between the focal and target actors, independent of the objective features of the interaction. The words rivalry and friendship can also both be used to refer to a relationship as well as the internal psychological state it creates. Further, we take the position that the relationship exists in the mind of the actor; if an actor feels rivalry, or friendship, towards another actor, then the relationship exists, regardless of the objective situation. This is why we discuss factors such as repeated competition as contributing to the formation of rivalry rather 
than being prerequisites for it to exist. Our conceptualization also leaves open the possibility of one-sided rivalry, such that one side considers the other a rival but this is not reciprocated.

It is also worth exploring in more detail how this conceptualization of rivalry overlaps with, and diverges from, the traditional definition of competition as a current state of opposing goals (Deutsch, 1949). We will refer to this as 'structural competition.' First, competition against one's rivals is clearly a form of competition more broadly; for rivalry to exist, there must be some competition for valued outcomes or opposition between goals, at least in the minds of the actor(s). However, due to its relational nature, rivalry differs from structural competition in some important ways. First, rivalry entails a focus on a specific, identifiable, opponent. With structural competition, the significance of one competitor versus another is simply driven by the level of objective threat each poses to the focal actor's goals, and thus competitors are often interchangeable with one another. Structural competition can take place between unknown or anonymous opponents, and, as we noted earlier, this is often how it has been studied. In contrast, given that rivalry represents a relationship, it is always directed toward a known competitor.

Second, rivalry, unlike structural competition, has a historical component to it.

Relationships are typically built up over a series of interactions, and thus rivalry cannot be fully captured by the characteristics of the current competitive setting. This is a critical distinctionalthough structural models of competition implicitly assume that history does not matter, we believe that it can play a substantial role. ${ }^{2}$ Finally, we cast a broad net when referring to "competitions against the target actor." As long as there is perceived competition in the actors' minds, this is sufficient, even if there are not any immediate objective rewards at stake. For

\footnotetext{
${ }^{2}$ Our conceptualization of rivalry also differs from work that has used 'rivalry' to indicate competitors of proximate hierarchical rank (Bothner, Kang, \& Stuart, 2007; Garcia, Tor, \& Gonzalez, 2006).
} 
example, rival athletes may feel as though they are in competition with one other even while training in the offseason.

\section{EXTANT RESEARCH ON RIVALRY}

Consistent with the distinction drawn above, a few researchers have recently begun to investigate rivalry as something more than a synonym for competition. Two main sets of findings have emerged from this research. First, we now have some insight into how and why rivalry forms - i.e., the factors that can lead competitors to place increased importance on competitive outcomes vis-à-vis certain other opponents, independent of objective stakes (Kilduff, 2014; Kilduff et al., 2010). First, similarity between competitors, by amplifying pressures towards social comparison and heightening the relevance of the competition to their identities (e.g., Festinger, 1954; Tesser, 1988), fosters greater rivalry. ${ }^{3}$ Second, repeated competition, in a process analogous to the "mere exposure" effect, whereby repeated exposure to a stimulus intensifies one's initial disposition towards it (Brickman, Renfield, Crandall, \& Harrison, 1972; Zajonc, 1968), can increase feelings of rivalry. That is, competitors who repeatedly compete develop greater and greater feelings of rivalry toward one another - an idea supported by research showing that repeated social comparison to a target makes that target increasingly likely to become a 'routine standard' of comparison, with whom comparisons carry greater weight for self-evaluations (Mussweiler \& Rüter, 2003). ${ }^{4}$ Third, closely-decided contests can contribute to

\footnotetext{
${ }^{3}$ Although it has not yet been established empirically, it is possible that certain key differences between competitors might also foster greater rivalry, particularly if these differences are along domains central to the competitors' identities. This would be consistent with some recent work suggesting that organizational members (Elsbach \& Bhattacharya, 2001) and individuals (Zhong, Phillips, Leonardelli, \& Galinsky, 2008) may sometimes derive identity from who they are not as much as from who they are. Generally, however, similarity fosters rivalry.

${ }^{4}$ Repeated competition between firms can also sometimes result in mutual forbearance, or a situation in which competitiveness and aggression is actually constrained, particularly amongst firms who compete across multiple
} 
rivalry by prompting greater counterfactual thinking, rumination, and emotional reactions (Kahneman \& Miller, 1986; Medvec, Madey, \& Gilovich, 1995; Medvec \& Savitsky, 1997), and creating expectations of future evenly-matched competition, which has been shown to heighten psychological stakes (Brehm, Wright, Solomon, Silka, \& Greenberg, 1983).

In support of these ideas, rivalry between NCAA basketball teams has been found to be positively related to similarity (in geographic location, success in basketball, and broader university characteristics), repeated competition (games played against each other) and evenlymatched past competition (narrower margins of victory, more evenly-matched head-to-head records; Kilduff, et al., 2010). Further, individuals within the general population report feeling greater rivalry towards competitors who are higher along these three dimensions (Kilduff, 2014).

The second main finding that has emerged is that rivalry appears to increase motivation and effort. Kilduff et al. (2010) observed a positive correlation between rivalry and defensive statistics in basketball. Kilduff (2014) found that people reported being more motivated against their rivals as compared to non-rival competitors, and that long-distance runners ran faster in races in which their rivals - identified based upon the antecedents of rivalry - were also present. Other work has observed heightened testosterone levels in soccer players prior to a match against a "fierce" rather than a "moderate" rival (Neave \& Wolfson, 2003), and has identified feelings of rivalry as a potential explanation for why bidders are more likely to exceed their bidding limits when facing a few, rather than many, competing bidders (Ku, Malhotra, \& Murnighan, 2005; Malhotra, 2010). There is also some work on the topic of international conflict that makes the same broad point that the intensity of conflict between nation states cannot be understood solely from the current situation - instead, histories of past interaction between states must also be 
considered (Goertz \& Diehl, 1993; Stinnett \& Diehl, 2001; Thompson, 1995). Research on rivalry is still very much in its infancy, however. Apart from a few studies linking rivalry to greater motivation, its consequences remain largely unexplored. Here, we examine the potential 'dark side' of rivalry, looking at its effects on unethical behavior.

\section{RIVALRY AND UNETHICAL BEHAVIOR}

The question of when and why people engage in unethical behavior is an important one for both academics and practitioners, given its costly and destructive consequences for individuals, organizations, and society. Consistent with prior researchers, we define unethical behavior as behavior that falls outside of generally accepted norms of moral behavior, such as cheating, lying, or stealing (Reynolds \& Ceranic, 2007; Treviño, Weaver, \& Reynolds, 2006). We focus primarily on unethical behavior that is directed at a target with the aim of harming, limiting the performance of, or gaining an advantage over, that target, in the context of competitive or mixed-motive interactions.

Existing research has identified a range of factors that can contribute to unethical behavior (for a review see Kish-Gephart et al., 2010), as well as the related construct of organizational misconduct, which includes organization-level unethical behavior as well as behavior that may be less intentional (for a review, see Greve, Palmer, \& Pozner, 2010). Both individual (e.g., age, gender, cognitive moral development) and environmental (e.g., norms, honor codes, organizational culture) factors can influence unethical behavior and organizational misconduct (Greve et al., 2010; Kish-Gephart et al., 2010; Mayer, Kuenzi, Greenbaum, Bardes, \& Salvador, 2009; Moore, Detert, Treviño, Baker, \& Mayer, 2012; Whitley, 1998).

Most germane to the current research, some prior work has identified competition as a driver of unethical behavior (e.g., Kohn, 1992; Hegarty \& Sims, 1978; Perry, Kane, Bemesser, \& 
Spicker, 1990; Vaughan, 1999). For example, in a business simulation, MBA students more often provided illegal 'kickbacks' to purchasing agents when they were placed in competition with one another, provided that this behavior benefited their performance (Hegarty \& Sims, 1978). However, there exist some exceptions to the positive link between competition and unethical behavior; for example, Schwepker (1999) found that salespeople's perceptions of the competitive intensity of their markets negatively predicted their intentions to behave unethically. Further, researchers have largely failed to outline the conditions under which this link is more or less likely to exist. In particular, it is unclear in past research whether or not any rivalry existed between the competitors being studied - thus, confounding rivalry and non-rival competition.

We propose that the effects of competition on unethical behavior will depend upon whether one is competing against a rival versus a non-rival. Specifically, we predict that competition against a rival will lead to increased unethical behavior as compared to non-rival competition. This prediction is grounded within longstanding models of ethical decisionmaking. Prominent models within the literatures on crime, academic dishonesty, and deception have proposed that people undergo cost-benefit analyses when deciding whether to behave unethically, weighing the perceived benefits of the behavior against the perceived costs (e.g., Becker, 1968; Eccles, 1983; Greve et al., 2010; Lewicki, 1983; Wigfield \& Eccles, 1992). Similarly, at the organization level, rational-choice perspectives posit that organizations weigh potential benefits and costs to their reputation in decisions to engage in misconduct (e.g., Karpoff, Lee, \& Vendrzyk, 1999; Kreps \& Wilson, 1982). Thus, because increased scarce resources or other desired outcomes are awarded to the winners of competition, a primary way in which competition may foster unethical behavior is by providing incentives for high-ranking performance, encouraging unethical behavior that confers a competitive advantage. Rivalry, 
given that it entails increased psychological stakes on top of the tangible stakes of competition, should further tip the scales in favor of unethical behavior.

Hypothesis 1 (H1): Actors will exhibit more frequent unethical behavior when competing against their rivals than when competing against non-rival competitors.

In addition to testing this primary hypothesis, we also conduct an initial investigation into the psychological underpinnings of rivalry, with the goals of more precisely illuminating the nature of rivalry and the mechanisms by which it increases unethical behavior. We focus on potential psychological mechanisms that fall within two general categories: increased psychological stakes and altered psychological orientations.

First, as suggested by prior theory on rivalry (e.g., Kilduff et al., 2010) and argued above, rivalry may increase unethical behavior by increasing the subjective importance placed upon competitive outcomes, which in turn will tip cost-benefit analyses in favor of unethical behaviors that can provide a competitive advantage. Within this category of increased psychological stakes, we investigate two specific mediators. First, competition against rivals may have greater implications for one's sense of self than competition against non-rivals. Work on the contingency of self-worth (CSW) argues that people have various domains in which they invest their self-esteem, such that success in these domains boosts self-esteem, and failure lowers it (Crocker \& Wolfe, 2001; Crocker, Luhtanen, Cooper, \& Bouvrette, 2003). Competition is one of the areas upon which self-worth can be contingent, and the self-esteem of people high on this dimension of CSW depends more heavily on their performance relative to others. The CSW framework has been applied primarily as a set of individual difference measures, however, competition as a contingency of self-worth may depend upon who one is competing with. Given that rivals are competitors who are more similar, who attract greater attention and social 
comparison, and with whom actors have longstanding competitive relationships, outcomes of competitions against rivals are likely to affect self-esteem to a greater degree than competition against non-rivals. Indeed, some prior work suggests that comparisons to more familiar others carry greater weight on our own self-evaluations (Locke, 2007; Mussweiler \& Rüter, 2003; Tesser, 1988). This increased CSW may then increase unethical behavior. Indeed, other work has observed positive relationships between CSW in academics and academic dishonesty (Covington, 1984; Niiya, Ballantyne, North, \& Crocker, 2008).

Hypothesis 2 (H2): Contingency of self-worth will mediate the link between rivalry and unethical behavior.

A second form of psychological stakes that may be increased by rivalry is concern over one's relative status, or level of social standing (e.g., respect and prestige; Anderson, John, Keltner, \& Kring, 2001; Blader \& Chen, 2011; Magee \& Galinsky, 2008). Again, in contrast to novel or anonymous competitors, rivals are competitors with whom actors have standing relationships and experience regular competition, which may also include expectations of future competition. As a result, people are likely to be more concerned about their status - or how others see them - relative to their rivals as opposed to non-rival competitors. In support of this idea, recent evidence suggests that people care more about their social status vis-à-vis wellknown members of their face-to-face groups than about their status in society more broadly (Anderson, Kraus, Galinsky, \& Keltner, 2012). Further, as mentioned above, rivalry in professional soccer players was associated with increases in testosterone (Neave \& Wolfson, 2003), and testosterone has been shown to correlate with both sensitivity to status-related information and motives to gain and maintain status (Liening, Mehta, \& Josephs, 2012; Ronay \& Galinsky, 2011; Schultheiss \& Rohde, 2002). The idea that we care more about our status 
relative to our rivals is also consistent with how we might think about rivalry from an evolutionary perspective: frequent, similar and evenly-matched individuals would have typically been those most likely to compete for reproductive opportunities, and status is a primary predictor of reproductive success (Barkow, 1975; De Waal, 1982; Ellis, 1994). In terms of the link between status concerns and unethical behavior, a recent study found that individuals were more likely to engage in undermining behaviors towards individuals they perceived to be a status threat (Pettit, 2012). Thus, in addition to potentially carrying greater consequences for one's internal sense of self, competition against rivals may also loom larger, psychologically, due to increased concerns about how the outcomes will influence the opinions of others.

Hypothesis 3 (H3): Relative status concerns will mediate the link between rivalry and unethical behavior.

In addition to increasing unethical behavior via increased psychological stakes, it is also possible that rivalry might alter competitors' mindsets or orientations heading into, and during, competition. A number of recent studies have demonstrated that unethical behavior is not always driven by the kind of calculative cost-benefit analysis that is central to traditional models (e.g., Becker, 1968; Eccles, 1983) - it can also be a product of impulses, emotions, goals and decision frames (Haidt, 2001; Kern \& Chugh, 2009; Reynolds, 2006; Sunstein, 2005; Tenbrunsel \& Messick, 1999; Tenbrunsel, Diekmann, Wade-Benzoni, \& Bazerman, 2010). For example, individuals who perceive a decision to be a 'business decision' are more likely to engage in unethical behavior than those who see it as an ethical decision (Tenbrunsel \& Messick, 1999).

We examine two types of psychological orientations or mindsets that might underlie the link between rivalry and unethical behavior. First, we examine the goals that individuals carry with them into competition. Theories of achievement orientation posit that individuals can adopt 
two broad types of goals within task settings (Dweck \& Leggett, 1988). Performance goals entail the desire to outperform others and demonstrate superior ability, whereas learning or mastery goals reflect the desire to develop one's competence and improve relative to one's own past performance. Even in a competitive setting, some individuals may focus primarily on defeating their opponents, whereas others care more about their performance and behavior relative to their own standards, or the extent to which they learned something valuable.

Past research has shown a link between performance approach goals and unethical behavior. Students adopting a performance approach goals are more likely to engage in academic dishonesty than students adopting mastery goals (Anderman, Griesinger, \& Westerfield, 1998; Anderman \& Midgley, 2004; Murdock, Hale, \& Weber, 2001). Similarly, "win-framed" negotiators, who are focused more on outperforming their negotiation counterparts than on achieving mutual benefits, are more likely to deceive their counterparts (Schweitzer, DeChurch, \& Gibson, 2005). As rivals incite greater social comparison pressure and greater motivation to win (e.g., Kilduff, 2014), it stands to reason that actors will adopt greater approach performance goals in competitions against their rivals. In other words, we expect rivalry to increase actors' focus on their relative performance and on the final outcome of winning in competition, to the detriment of other concerns, including the means used to achieve those outcomes and whether such behavior is ethical. For the sake of brevity, we refer to increased performance approach goals as a 'performance orientation.'

Hypothesis 4 (H4): A performance orientation will mediate the link between rivalry and unethical behavior.

Second, it is possible that rivalry could increase feelings of threat. Past researchers have argued that people respond to task settings with evaluative components and/or consequences for 
their well-being, progress, and self-esteem with either a sense of challenge or a sense of threat, which have different physiological profiles (Blascovich \& Mendes, 2000; Blascovich, Mendes, Hunter, \& Salomon, 1999). Given its heightened psychological significance, competition against rivals might very well invoke one of these mindsets. In particular, though there is less existing evidence to support this connection than the other proposed mediators, if rivalry invokes a sense of threat, this might help explain why it leads to greater unethical behavior (Fast \& Chen, 2009; Kouchaki \& Desai, 2014).

Hypothesis 5 (H5): Feelings of threat will mediate the link between rivalry and unethical behavior.

In summary, we consider two sets of potential mediators that can explain the link between rivalry and unethical behavior. We examine two forms of increased psychological stakes - one, greater contingency of self-worth, that is internally focused, and the other, increased status concerns, that focuses on the opinions of others. We also examine two psychological orientations - one, a performance orientation, that is approach-oriented, and the other, feelings of threat, that is avoid or prevention-oriented. We test each of these mediators in Study 4 and also explore the possibility of serial mediation (e.g., Hayes, 2013). That is, we test the following theoretical model: rivalry leads increased psychological stakes, which causes people to adopt a different orientation during competition, which causes them to engage in increased unethical behavior.

\section{OVERVIEW OF STUDIES}

We present four studies that investigated the link between rivalry and unethical behavior. Study 1 examined rivalry and unethical behavior in a real-world, high-stakes context, professional soccer. Study 2 explored the extent to which university students deceived 
counterparts from a rival versus a non-rival university, whilst controlling for other possible explanatory variables such as dislike and perceived tangible stakes. Study 3 sought to replicate the effect of rivalry on unethical behavior within the context of a business scenario, examining the extent to which people were deceitful in their opening statements of a negotiation. Finally, Study 4 sought to shed greater light on the psychology of rivalry and the factors that might explain its effects on unethical behavior.

\section{STUDY 1: AN ARCHIVAL ANALYSIS OF MISCONDUCT IN SOCCER}

We begin by examining the link between rivalry and unethical behavior (Hypothesis 1) in a real-world context involving high stakes, face-to-face competition. Specifically, we examined unethical conduct among professional soccer players in Italy. This setting was well-suited for testing our hypothesis, for several reasons. First, this is a setting in which fierce rivalries are known to exist. Second, this is a setting with high stakes, for both individual players and teams. Thus, we could be confident that the competitors were fully invested in these contests, and that we were studying a setting in which competitive behavior carried significant consequences. Third, soccer provides a face-valid and accepted measure of unethical behavior, in the form of yellow and red cards, which we describe below. Finally, sports organizations have long been recognized as an excellent testing ground for management topics (e.g., Day, Gordon, \& Fink, 2012; Marr \& Thau, 2013; Staw \& Hoang, 1995).

\section{Setting and Sample}

Our sample consisted of 2,788 matches played between 2002 and 2009 in Serie A, Italy's top soccer league. Rivalry is known to exist in this league, most often between teams co-located in the same city. For example, Genoa C.F.C.'s coach once described the Genoa derby (intra-city rivalry) between Genoa C.F.C. and U.C. Sampdoria by saying: "The only thing that counts in 
Genoa is the derby. If you don't win it, it's like robbing a bank and getting out with a suitcase full of rags" (Flamigni, 1995). Serie A includes 20 teams (18 teams in 2002 and 2003), and matches are played between August and May each year. Data on these matches were collected online from ESPN Soccernet, Gazzetta (www.gazzetta.it), Spaghetti Italia (www.spaghettitaliani.com) and http://digilander.libero.it/. We first present analyses of these data at the match level (the variables described below are at the match level; correlations between these variables are displayed in Table 1). Then, as a robustness check, we present analyses at the player-match level, which allows for additional player-level controls.

\section{Measures}

Unsportsmanlike conduct. Our dependent variables were the number of yellow and red cards issued in each match. Yellow and red cards are given to players by referees as punishment for a variety of infractions that are generally related to unsportsmanlike or unethical behavior; yellow cards are given for moderate infractions and red cards for more serious infractions. ${ }^{5}$ These can include dangerous tackles that risk injuring other players as well as attempts to deceive the referee by "taking a dive."

Rivalry. To assess rivalry between teams, we created a dummy variable indicating whether teams were located within the same city. As illustrated by the quote above, anecdotal evidence indicates that co-located teams are generally the fiercest rivals (for an in-depth description of the intensity of these intra-city rivalries in the English Premier League, see also http://espn.go.com/espn/feature/story/_id/12448117/the-premier-experience). Furthermore, geographic proximity was identified by Kilduff et al. (2010) as by far the single strongest predictor of rivalry between athletic teams.

\footnotetext{
${ }^{5}$ See the International Federation of Association Football's "Laws of the Game" for more detail: http://www.fifa.com/mm/document/affederation/generic/81/42/36/lawsofthegame_2010_11_e.pdf
} 
Control variables. We collected a variety of control variables that might influence teams' tendencies to receive yellow and red cards. First, we measured the proximity in standings between pairs of teams, as the absolute difference between the two teams' points in the seasonlong standings. ${ }^{6}$ We considered this to be a rough measure of the objective stakes of the contest - teams who are closer to one another in the season-long standings generally have more at stake when they play one another because they are vying for ranking within the league standings. Second, we collected similarity in recent performance, to account for the possibility that matches between more evenly-matched teams - in terms of how they are currently performing - are objectively more intense, independent of rivalry. This was measured as the absolute difference between the two teams' points earned during their past three matches. It is worth noting that similarity in performance, measured by these first two control variables, is thought of as an antecedent to rivalry. However, in terms of driving rivalry, the evidence suggests that it is longterm similarity in performance that matters rather than recent similarity (Kilduff et al., 2010, see pp. 956-957 for details). Nonetheless, in addition to the models presented here, we ran all models with these control variables excluded and observed no meaningful differences in the results of our hypothesis tests.

Insert Table 1 about here

Third, to control for the possibility that yellow and red cards are more common at certain stages of the season - perhaps due to differences in perceived objective stakes - we created two dummy variables (mid-season and late-season) that indicated which third of the season the

\footnotetext{
${ }^{6}$ Teams earn 3 points for a win, and 1 point for a draw. Season-long standings are the sum of these across all games played, and determine which teams receive bids into lucrative tournaments (high finishers) and which teams are 'relegated' to a lower division (low finishers).
} 
match was played in. Fourth, we collected attendance data for each match, because it seemed possible that greater fan attendance might promote greater arousal amongst players, perhaps making them more likely to engage in the kind of unethical and aggressive behavior deserving of yellow and red cards. Fifth, twenty of the matches $(0.7 \%)$ in our sample had no crowd, as a result of disciplinary action against teams and fans; we created a dummy variable (no crowd) as a control. Sixth, we measured the absolute margin of victory in the match (goal differential), as more closely-decided matches might also foster greater arousal. Seventh, we measured referees' propensity to issue yellow and red cards, equal to the average number of cards (yellow or red, depending on the analysis) that each match's referee had issued across all matches he had refereed up to that point in the season (avg. \# of cards given by referee). ${ }^{7}$

\section{Results}

The average number of yellow cards issued to players was significantly higher in rivalry matches as compared to non-rivalry matches, $M=6.03$ vs. $M=4.25, t(2786)=6.12, p<.001, d$ $=.91$, eta-squared $=.013$. We then ran a Poisson regression analysis that included our control variables. As shown in Model 1 of Table 2, the positive relationship between the rivalry dummy and the frequency of yellow cards was positive and significant, Wald $\chi^{2}=40.23, p<.001$. Red cards were also more common in rivalry matches than non-rivalry matches, $M=.50 \mathrm{vs.} M=$ $0.33, t(2786)=1.90, p=.057, d=.27$, eta-squared $=.001 ;$ as shown in Model 2, this held up in a Poisson regression with controls, Wald $\chi^{2}=8.15, p=.004$. Thus, Hypothesis 1 was supported.

Insert Table 2 about here

\footnotetext{
${ }^{7}$ We ran additional models in which we controlled for referees' averages for the entire season, regardless of when the game was played. This did not result in any meaningful differences in results.
} 
To address concerns over a lack of independence within these data, we also ran these models with team-level fixed effects (dummy variables) included for both the home and away teams. This served to control for any team-level tendencies toward earning yellow and red cards, as well as eliciting them from opponents. The results were not meaningfully different: rivalry was still associated with higher rates of yellow (Wald $\chi^{2}=35.97, p<.001$ ) and red cards (Wald $\left.\chi^{2}=4.24, p=.039\right)$. As an additional robustness check, we conducted similar analyses at the player-match level of analysis, which allowed us to control for a number of other factors that varied at the player-match and player levels. These included: player position (goalkeeper, defender, midfielder, or forward), minutes played in the match, whether or not the player was a substitute, the average number of yellow (or red) cards that player had received up to that point in the season, and whether the player was playing at home or away. Our sample for these analyses consisted of 100,310 matches played by individual players between 2002 and 2009 (the same sample of matches used for match-level analyses).

We ran two logistic regression analyses predicting whether or not a player earned a yellow or a red card in a given game, with all match-level, player-level, and player-game level control variables included. In the model for yellow cards, rivalry was positively and significantly associated with likelihood of earning a yellow card, Wald statistic $=54.27, p<$ .001 , odds ratio $=1.73$. The logistic regression for red cards yielded a Wald statistic for rivalry of $9.12, p<.01$, and odds ratio of 1.99 .

\section{Discussion}

Study 1 found that professional soccer players were more likely to be penalized for unsportsmanlike behavior when playing against rival teams, as compared to matches against other teams. Supporting the idea that rivalry promotes unethical behavior independent of more 
objective or stakes-based drivers of competitive intensity, these effects held when controlling for proximity between teams in the season standings, proximity between teams in recent performance, and the margin of victory in the match.

There are, however, some limitations to this study that are worth noting. First, our measure of rivalry was indirect and may not have captured all of the rivalries existing in the Serie A league, as some pairs of rival teams may not be co-located. However, this should have worked against finding a significant difference between matches classified as rivalry versus nonrivalry. Second, although yellow and red cards are fairly face-valid measures of unethical behavior, they are occasionally issued for behaviors that are less directly unethical (e.g., taking one's jersey off after scoring a goal). Third, yellow and red cards are based upon subjective judgment calls by referees, so one possible alternative explanation for our findings could be that referees are more likely to penalize players in rivalry matches, even if their behavior is not any different. The plausibility of this explanation, however, is reduced by the fact that referees are extensively trained on what constitutes a punishable offense, are expected to maintain consistent standards across matches, and are promoted and demoted based on their performance. Fourth, although we controlled for proximity in league standings as a rough measure of the objective stakes of the contest, this is not a perfect measure, so we cannot definitively rule out objective stakes as a possible alternative explanation. Overall, as is the case with all archival studies, we are constrained in our ability to make causal inferences; Studies $2-4$ involved experiments to provide a better demonstration of a causal connection between rivalry and unethical behavior. 
In Study 2, we conducted an experimental test of Hypothesis 1. We used an established and longstanding organizational rivalry as the context for this study, and examined individuals' use of deception for personal gain.

\section{Participants and Design}

Participants were 70 undergraduate students from The Ohio State University in Columbus, $\mathrm{OH}\left(55.7 \%\right.$ male; $M_{\mathrm{age}}=21.1$ years; $\left.S D=1.76\right)$; our sample size, and thus statistical power, in this study was limited by the number of participants we succeeded in recruiting, as described below. We selected this institution for study due to its intense and long-running rivalry with the University of Michigan. The rivalry dates back to at least 1897 , when the two first met on the football field, and was recently named by the Huffington Post as the \#1 interuniversity rivalry in the United States. ${ }^{8}$ Participants were randomly assigned to either interact with a counterpart from either a rival or non-rival academic institution.

\section{Procedure}

Participants were recruited via a publicly available list of student clubs and associations (including fraternities and sororities) at the university. Specifically, the officers of these associations were emailed and asked to distribute the survey to their members; for each member that participated, the association received $\$ 5$.

Participants completed an online survey described as examining inter-university attitudes between students at four public U.S. universities. They were told that they would engage in a joint decision-making task with a randomly-selected student from one of the other universities.

Rivalry manipulation. Participants were randomly assigned to be paired with a student from the University of Michigan (rival; $\mathrm{N}=26$ ), the University of California, Berkeley (non-

\footnotetext{
${ }^{8}$ http://www.huffingtonpost.com/2011/09/01/the-10-best-collegerival_n_944635.html\#s346517\&title=Ohio_State_vs
} 
rival; $\mathrm{N}=23$ ), or the University of Virginia (non-rival; $\mathrm{N}=21$ ). Counterparts were computer simulated, not actual people. We chose these universities because all of them, including Ohio State, are ranked in the top 16 U.S. public universities, according to U.S. News and World Report, and the opponent schools in particular are very closely matched on academic status. ${ }^{9,10}$

Participants then completed measures of perceived tangible stakes of competition, as well as dislike felt towards members of the other university. These factors might covary with rivalry and also affect unethical behavior, and were thus used as control variables. Following this, participants completed a decision-making task in which they had the opportunity to lie to their counterpart for personal gain. The survey concluded with measures of demographics and perceived institutional status, as well as manipulation and suspicion checks, and a debriefing.

\section{Measures}

Manipulation check. Four items assessed felt rivalry (e.g., "I consider this person to be a rival" and "I feel rivalry towards the university that this person is affiliated with"; $\alpha=.93 ; M=$ $3.80, S D=2.12)$.

Deception. Participants played a version of Gneezy's (2005) Deception Game, which has previously been used to study unethical behavior in organizations (Zhong, 2011), and was referred to as an "interaction." They were told that the interaction involves two players, an 'advisor' and an 'advisee'. The advisee must choose between two options, A and B, which determine the payoffs for each party. One of these pays the advisee $\$ .80$ and the advisor $\$ .40$, and the other pays the advisee $\$ .40$ and the advisor $\$ .80$. However, only the advisor knows which option is which. Participants were assigned to the role of advisor and given a choice of

\footnotetext{
${ }^{9} \mathrm{http} / / /$ colleges.usnews.rankingsandreviews.com/best-colleges/rankings/national-universities/top-public ${ }^{10}$ Ohio State plays Michigan in football every year, and had played UC Berkeley the previous two years at the time of our survey.
} 
two messages that they could send to their counterpart. The first was true, telling the advisee "Option A will pay you more than Option B." The second was a lie, "Option B will pay you more than Option A." The advisor was told that roughly $80 \%$ of people in the advisee role tend to trust the message sent (Zhong, 2011). Thus, our dependent measure involved a choice between telling the truth and telling a lie for purposes of self-gain, a common ethical dilemma.

Control variables. Participants rated their agreement with "The tangible stakes (e.g., money, resources) associated with competitions between my university and this other university are very high" from "1 - Strongly disagree" to "7 - Strongly agree" $(M=3.98, S D=1.84)$. They rated dislike of their counterpart and associated institution with three items (e.g., "I dislike this other university" and "I dislike students, alumni, or other affiliates of this university"; $\alpha=$ $.81 ; M=2.41, S D=1.45)$. Finally, we measured participants' perceptions of the academic, and athletic, status of all four universities on a scale from "1 - Low status" to "7 - High status."

\section{Results}

Manipulation and suspicion checks. Five participants $(7.1 \%$; two each for participants matched with a counterpart from UC Berkeley and Michigan, one that was matched with Virginia) indicated being suspicious, e.g., "I knew there was no real counterpart." We present results excluding these individuals; including them does not significantly change our results. Also, because no significant or meaningful differences were observed between participants matched with a counterpart from UC Berkeley versus Virginia, we report results with these conditions combined.

Participants matched with a rival (i.e., a counterpart from Michigan) reported feeling much higher levels of rivalry than participants in the non-rival conditions ( $M=5.70$ vs. $2.52, t$ $(63)=8.83, p<.001 ;$ all reported tests are two-tailed). 
Deception. In support of H1, participants in the rivalry condition were far more likely to lie to their counterparts than participants in the other conditions, $M=50.0 \%$ vs. $12.2 \%, \chi^{2}(1,65)$ $=11.20, p<.001, d=1.09$. This effect held up in a logistic regression analysis (Wald statistic $=$ 4.24, $p=.040$ ), when controlling for tangible stakes (Wald $=2.08, p=.15$ ), dislike (Wald $=.00$, $\mathrm{p}=.95$ ), and perceived academic and athletic status of the counterpart's university (Wald $=1.04$, $\mathrm{p}=.31$ and $\mathrm{Wald}=1.51, \mathrm{p}=.22$, respectively). The odds ratio for the rivalry dummy was equal to 9.26 , indicating that the odds of participants in the rivalry condition using deception was more than nine times that of participants in the non-rivalry conditions. We also ran a model in which we examined the interaction between rivalry and dislike; the rivalry manipulation remained significant $($ Wald $=4.33, p=.038)$ and neither dislike (Wald $=1.07, p=.30)$ nor the interaction term was significant $($ Wald $=.57, p=.45)$.

\section{Discussion}

Study 2 found that participants were more likely to deceive counterparts from a rival organization than those from a non-rival organization. This occurred independent of dislike, perceived tangible stakes, and perceived status of the counterpart's institution.

\section{STUDY 3: DECEPTION IN NEGOTIATIONS}

Study 3 sought to replicate our main finding in a different context, and with a different manipulation of rivalry. Online participants were matched with an ostensible counterpart and given information about the roles that they, and their counterparts, had been assigned to play, as well as the relationship and history that existed between the two parties. We then examined the extent to which participants were deceitful in their initial communications to their counterparts, in an attempt to extract greater value from the negotiation.

\section{Participants and Design}


Participants were via 101 adults recruited via Amazon Mechanical Turk (MTurk), an online service that matches 'workers' with 'requesters' who post jobs to be completed (see Buhrmester, Kwang, \& Gosling, 2011 for more detail on this service as well as analyses that confirm the quality of responses). Participants were paid a base amount of $\$ 1$, plus bonuses earned, for an online study that took about 10 minutes to complete. $65.3 \%$ of participants were female, and they were 32.4 years old on average $(S D=10.5)$, with an average of 11.8 years of full-time work experience $(S D=10.7)$. Participants were randomly assigned to one of two conditions, rivalry $(\mathrm{N}=49)$ and non-rival competition $(\mathrm{N}=52)$.

\section{Procedure and Rivalry Manipulation}

Participants were informed that they would be taking part in a study of virtual negotiations. They were told that they would engage in an online negotiation with another worker and that their performance in the negotiation would affect the size of the bonus they received. They were then given their role instructions, which began as follows:

You will be playing the role of 'Taylor', owner and CEO of a car dealership located in a mid-sized town (population 100,000). Your counterpart, Runner33, is playing the role of 'Jamie', who owns and runs a competing car dealership in the same town.

At this point, we introduced the manipulation of rivalry versus non-rival competition. In the rivalry condition, participants were told:

You and Jamie have a long history of competing with one another. You both opened car dealerships at almost the same time, about 20 years ago, and in the years since, you have repeatedly competed for customers, market share, and to have the best reputation in town. The two of you have been very evenly matched over the years, with neither side 
ever taking a decisive lead. As result of this, you feel a good deal of rivalry towards Jamie and his car dealership, and you get the impression that these feelings are mutual. In the non-rival competition condition, participants were told:

You and Jamie do not have much of a history together. You have been operating your dealership for about 20 years, but Jamie's dealership opened fairly recently, so the two of you have not yet experienced direct competition with one another.

All participants were then told:

At stake in the current negotiation is the sale of a piece of repair equipment that you no longer need. Jamie has expressed interest as a potential buyer. You originally purchased this equipment for a cost of $\$ 75,000$, three years ago, which is still the price for which it sells brand new. A third party (not Jamie) has also expressed interest in acquiring the equipment, and has made you an offer of $\$ 25,000$. However, you are hoping that you can sell the equipment to Jamie for more than that. You also understand that it is possible that Jamie may include some non-monetary considerations - such as used vehicles or access to distribution channels - as part of any offer made.

Participants were then asked to take a moment to put themselves in this situation and imagine how they would feel. They were then given the following instructions:

As a result of your prior experience with negotiations, you have learned that having existing offers in hand can be a source of power. In other words, when multiple bidders are competing to buy the same item, the seller can sometimes play the bidders off of one another, using each one's bids to get the other to bid higher. Thus, the higher the offer in hand, the greater the power of the seller to extract a higher price from the buyer. In the current situation, Jamie has no knowledge of whether or not you have any existing 
offers on the repair equipment, or the amount of these offers. Furthermore, you are confident that Jamie will not find out. However, you are planning to tell Jamie that you have another offer because, as described above, you know that this is likely to help your position.

As an incentive for you in this negotiation, for every $\$ 1,000$ above $\$ 20,000$ that you are able to sell the equipment for, you will earn an additional $\$ .02$ bonus. Thus, you are currently guaranteed at least a $\$ .10$ bonus because of your existing offer of $\$ 25,000$, which you can always accept if Jamie is not willing to pay any higher. If you can get Jamie to agree to pay more, you will earn a higher bonus.

To begin the negotiation, you must decide what to tell Jamie about your existing offer. You realize that this is likely to set the price around which the negotiation will take place. Please enter your initial communication to Jamie below, complete with details $\underline{\text { about your existing offer. }}$

Thus, the negotiation was constructed such that participants had a financial incentive to lie about the size of their existing offers, and this was equivalent across conditions. It was from these opening statements that our measure of unethical behavior was drawn, as described below. After making their opening statements, participants completed a manipulation check and were then informed that the study was being cut short. They were told that, because the chat protocol was still being perfected, this study was serving as pretest for the main study and that they would not engage in the negotiation with their counterpart. They still received a $\$ .10$ bonus, however. The survey ended with a check for suspicions and basic demographic questions.

\section{Measures}


Manipulation checks. Rivalry was measured with a four-item scale (Kilduff, 2014; e.g., "I feel rivalry towards this person," $\alpha=.85, M=3.43, S D=1.99$ ).

Deception. Participants' opening statements were examined for deception. There were a range of opening statements, and after reading them, we created six different categories in which to group them. A research assistant who was blind to condition and our hypothesis categorized each statement. Twenty (19.8\%) participants told their counterparts the 'complete truth,' indicating that they had a single existing offer of $\$ 25,000$ (category 1; e.g., "I currently have an eager buyer willing to pay $\$ 25,000$ for the equipment.”). Thirty-six (35.6\%) participants effectively skirted the issue, either by not mentioning that they had an existing offer, or by not offering any information about its magnitude (category 2; e.g., "I have a piece of equipment that I am willing to sell. I will settle the transaction at \$30,000. Do you accept?”). Both of these categories of responses were coded as not exhibiting unethical behavior (deception $=0$ ).

Twenty-seven participants (26.7\%) lied directly, in numerical terms, about the amount of the offer they had in hand (category 3; e.g., "I have been offered $\$ 35,000$ for this part, however I would prefer to sell it to you. Make an offer.”). The remaining eighteen participants (17.8\%) employed some form of deception that was less direct than a numerical lie. This included participants who lied about the amount of the offer in words (category 4; 5.0\%; e.g., "Hello Jamie, glad to hear you're interested in my hardware. I already have an offer for it so you'll have to talk me into giving it to you for a good price. I expect to get at least $1 / 2$ what I paid as the other offer is just a bit over that. What do you say, buddy?"), exaggerated the amount of the offer by describing it as 'very good,' 'very generous,' or something similar (category 5; 7.9\%; e.g., "Hi Jamie, I'm glad to hear of your interest in the repair equipment I'm selling. I have a very strong offer already from a third party, but I would be happy to work with you for a fair 
price") ${ }^{11}$, or indicated having multiple offers (category $6 ; 5.0 \%$; e.g., "The part you are interested in is highly sought after and I have a few offers...I can sell it to you for 50,000"). To conduct our main analysis, we split the six categories of opening statements described above into two broad categories, ethical (categories 1 and 2), and unethical (categories $3-6$ ).

\section{Results}

Manipulation and suspicion checks. Thirteen participants (12.9\%) indicated being suspicious, e.g., "I suspected early on that I would not actually be communicating with a real person." We present results excluding these individuals. There was a higher rate of suspicion in the rivalry condition than in the non-rival competition condition (10/49 (20.4\%) vs. $3 / 52(5.8 \%)$, $\left.\chi^{2}(1,101)=4.82, p=.028\right)$, but all analyses yield qualitatively equivalent levels of significance when suspicious individuals are included. Participants in the rivalry condition reported higher levels of rivalry than participants in the non-rival competition condition $(M=5.12$ vs. $3.02, t(86)$ $=8.28, p<.001)$.

Deception. In support of our main hypothesis, $56.4 \%$ of participants in the rivalry condition used some form of deception, versus $32.7 \%$ of participants in the non-rival competition condition, $\chi^{2}(1,88)=5.00, p=.025, d=.49$. We then looked more closely at the categories of deception employed. In terms of direct lying about the numerical value of the existing offer (category 3), there was a non-significant trend in favor of greater deception in the rivalry condition, $M_{\text {Rivalry }}=28.2 \%$ vs. $M_{\text {Non-rival competition }}=24.5 \%, \chi^{2}(1,88)=.16, p=.694$. However, participants in the rivalry condition were significantly more likely to employ the other, less direct, forms of deception (categories $4-6$ ) than were participants in the non-rival competition condition, $M_{\text {Rivalry }}=28.2 \%$ vs. $M_{\text {Non-rival competition }}=8.2 \%, \chi^{2}(1,88)=6.17, p=.013, d=.54$.

\footnotetext{
${ }^{11}$ We classified highly positive characterizations of the existing offer of $\$ 25,000$ as indirect deception due to the fact that the equipment was only three years old, in good working order, and sold new for $\$ 75,000$.
} 


\section{Discussion}

Study 3 provided additional evidence for our main hypothesis, finding that participants playing the role of a car dealership owner were more likely to use deception in their opening negotiation statements when they believed that their counterpart was a rival, as opposed to a nonrival. Interestingly, we found that this was driven primarily by an increase in the use of more indirect forms of deception. Although not a primary focus of this paper, we return to this in the general discussion and identify this as a potential area for future research.

\section{STUDY 4: PSYCHOLOGICAL MECHANSIMS}

Study 4 sought to build upon the findings of Studies $1-3$ by exploring the psychological mechanisms underlying the link between rivalry and unethical behavior. Participants were asked to recall a personal rival, non-rival competitor, or acquaintance, and then imagined that they were going to negotiate with this person in a scenario very similar to Study 3. Participants indicated what their opening statements would be, which were coded for deception as in Study 3, and then rated their willingness to use a range of ethically-questionable negotiation tactics. Finally, they rated their feelings towards the negotiation and their imagined counterparts along a number of dimensions, which were assessed as potential mediators. As described above, we examined two types of psychological stakes (contingency of self-worth and status concerns) and two psychological orientations (a performance orientation and feelings of threat).

We decided to employ the recall method, in which people held in mind real personal rivals, because we thought it would provide the best insight into people's feelings towards their rivals and thus offer us the best chance of understanding why rivalry increases unethical behavior, even in settings that do not involve intergroup dynamics (which may have played a role in Studies 1 and 2). Study 4 also extended the prior studies by adding a non-competition 
control condition, which allowed us to get a sense for how rivalry affects unethical behavior in general, compared to interactions and relationships that are not competitive.

\section{Participants and Design}

Participants were via 243 adults recruited via MTurk. Participants were paid \$1.40 for an online study that took about 15 minutes to complete. $50.6 \%$ of participants were male, and they were 31.1 years old on average $(S D=10.5)$, with an average of 10.2 years of full-time work experience $(S D=10.0)$. Participants were randomly assigned to one of three conditions, rivalry $(\mathrm{N}=79)$, non-rival competition $(\mathrm{N}=81)$, and control $(\mathrm{N}=83)$.

\section{Procedure and Rivalry Manipulation.}

In the rivalry condition, participants were asked to recall a competitor towards whom they felt rivalry, as follows (Kilduff, 2014):

"Please try to think of someone you have competed against who you feel or felt rivalry towards (for instance, someone you have repeatedly competed against and/or have been evenly-matched with). This competition could be on anything, big or small. Please describe this person and what you competed on."

In the non-rival competition condition, participants were told:

"Please try to think of someone you have competed against who you do/did NOT feel any rivalry towards (for instance, someone you only competed against one time and/or someone you have NOT been very closely-matched with). This competition could be on anything, big or small. Please describe this person and what you competed on."

Lastly, participants in the control condition were asked to think of an acquaintance. All participants were also told that the person they thought of should not be a "spouse, significant other, or family member," because interactions with such individuals are apt to be 
unique. Participants were then asked to imagine that they were preparing to negotiate with the person they had just described. As in Study 3, they were told that they and their counterparts each owned competing car dealerships within the same mid-sized town and were going to negotiate over the sale of a piece of equipment. The negotiation was described exactly as in Study 3 , including the information that the participant had a standing offer of $\$ 25,000$, with two exceptions. First, no mention of the existing relationship or history between the individuals and their dealerships was made, as the rivalry manipulation had already taken place. Second, as this was a simulated negotiation, there was no mention of a bonus tied to their performance. Participants were asked to indicate what their opening statement would be, and to rate their willingness to employ a number of ethically-questionable negotiation tactics. Consistent with our main theoretical arguments, we expected participants to indicate greater willingness to behave unethically towards their rivals than towards non-rival competitors or acquaintances. However, given the prior mixed findings surrounding the effects of general competition on unethical behavior and the fact that prior work may have lumped rivalry in with competition, we did not make any a priori predictions regarding differences between the non-rival competition and control conditions. Following our dependent measures, participants completed items related to our proposed mediators, items to be used as control variables, and a manipulation check.

\section{Measures}

Manipulation checks. Rivalry was measured with the same 4-item scale used in Study 2 $(\alpha=.89, M=3.14, S D=1.88)$.

Deception. Participants were asked to provide hypothetical opening statements and these were coded for the use of deception as in Study 3. Eighty-three (34.2\%) participants told their counterparts the 'complete truth,' indicating that they had a single offer of $\$ 25,000$ (category 1 ), 
and eighty-seven $(35.8 \%)$ either did not mention that they had an existing offer, or did not offer any information about its magnitude (category 2). Amongst those who engaged in some form of deception, thirty-five participants (14.4\%) lied directly in numerical terms (category 3), seven $(2.9 \%)$ lied about the amount of the offer in words, seventeen $(7.0 \%)$ exaggerated the amount of the offer by describing it as 'very good,' 'very generous,' or something similar (category 5), and fourteen $(5.8 \%)$ indicated having multiple offers (category 6).

Unethical negotiations tactics. Participants' unethicality was also assessed with seven items drawn from the Self-reported Inappropriate Negotiation Strategies scale (SINS; Robinson, Lewicki, \& Donahue, 2000), which has been used by a number of researchers as a measure of unethical behavior (e.g., Cohen, 2010; Hershfield, Cohen, \& Thompson, 2012; Pierce et al., 2013; Ruedy \& Schweitzer, 2010). Participants indicated their willingness to use a variety of ethically-questionable behaviors and tactics such as "Intentionally misrepresent factual information in order to support your negotiating arguments or position," "Promise things you know you can't (or won't) deliver" and “Acquire negative personal information about your opponent and use that information to force them to give you what you want." Participants rated these items on a scale from 1 ("Definitely would not use") to 7 ("Definitely would be willing to use") $(\alpha=.75 ; M=2.91 ; S D=1.08)$.

Mediators. Following the dependent measures, we asked participants a range of questions about their feelings towards the people they had imagined negotiating against, which were based on our theoretical discussion of potential mediators of the effects of rivalry on unethical behavior. Items were worded in the present (as listed here) or past tense, depending upon participants' response to the question "Do you currently compete with this person?" 
In terms of psychological stakes, we measured contingency of self-worth, or the extent to which participants' sense of self-worth depended upon their performance relative to their counterparts, with three items (adapted from Crocker et al., 2003; e.g., "It is important to my personal sense of success and accomplishment to outperform this person"; $\alpha=.84 ; M=3.58 ; S D$ $=1.71)$. We measured the extent to which participants were concerned with their status relative to their counterparts with five items (Blader \& Chen, 2011; e.g., "I strive to have higher status than this person," "I am rarely concerned with how my status compares to this person" (reversecoded); from " 1 - Not at all" to 7 - "Very much"; $\alpha=.78 ; M=3.68 ; S D=1.41$ ).

In terms of psychological orientations, we measured the extent to which participants adopted a performance orientation in the imagined negotiation with their counterparts with two items (adapted from Elliot \& Church, 1997; "My main goal would be to outperform this other person" and "I would strive to maximize the value I claimed relative to this other person"; from "1 - Not at all" to 7 - "Very much"). As a complement to this, we also created two items that more explicitly examined the trade-off between focusing on performance outcomes versus process ("When competing against this person, I am more concerned about whether I win than how I win," and "When I am competing against this person, what matters to me is the final outcome rather than how it was reached"). These four items showed high inter-item reliability and were thus combined into an aggregate measure of adopting a performance orientation $(\alpha=$ $.77 ; M=3.50 ; S D=1.40) .{ }^{12}$ For comparison purposes, we also measured adoption of a mastery orientation (adapted from Elliot \& Church, 1997; two items; e.g., "My main goal would be to improve my negotiation skills and mastery"; $\alpha=.76 ; M=4.92 ; S D=1.57)$. Finally, we assessed the extent to which participants would see the negotiation as threatening, and challenging.

\footnotetext{
${ }^{12}$ We also ran all relevant analyses using only the established two-item measure, and results were qualitatively identical.
} 
Although these states are best assessed via physiological measures (e.g., Blascovich et al., 1999), here we settled for self-report measures (e.g., Meijen, Jones, McCarthy, Sheffield, \& Allen, 2013; Tomaka, Blascovich, Kibler, \& Ernst, 1997), while acknowledging that exploration of the physiology of rivalry is an important avenue for future research. We asked participants to indicate the extent to which six adjectives would accurately describe their feelings about the imagined negotiation (from " 0 - Not at all" to 5 - "Very much so"; threat: "frightening," "threatening," "fearful"; $\alpha=.84 ; M=2.47 ; S D=1.22$; challenge: "exciting," "challenging," "stimulating"; $\alpha=.74 ; M=4.08 ; S D=1.12)$.

Control variables. We collected two control variables. First, we measured perceived tangible stakes of competition for participants in the rivalry and non-rival competition conditions, as applied to their actual competitions against this person ("How high were the tangible stakes (e.g., money, career success, grades, athletic success, etc.) associated with your competition(s) against this person?"; 1 ("Nothing tangible at stake") to 7 ("Very high"); $M=$ 3.63; $S D=1.95$ ). Although the described tangible stakes of the negotiation were held constant across conditions, some of our proposed mediators focused on participants' feelings towards their counterparts more generally, and we wanted to ensure any relationships between these and rivalry were not driven by perceived tangible stakes. Second, we collected a measure of proximity in rank ("I am closely ranked to this person"; 1 ("Not at all") to 7 ("Very much"); $M=$ 4.54; $S D=1.85$ ), because a potential alternative explanation for any link between rivalry and status concerns could be that rivals are simply competitors who are more closely ranked to ourselves (indeed, some researchers in the past have operationalized rivalry in this fashion; e.g., Garcia, Tor, \& Gonzalez, 2006). Across participants in the rivalry and non-rival competition conditions, rivalry was found to be moderately correlated with perceived tangible stakes $(r(160)$ 
$=.28, p<.001)$, and weakly correlated with proximity in rank $(r(160)=.16, p=.05)$; however, all analyses described below yield qualitatively equivalent levels of significance when these measures are included as control variables, so we do not discuss them further.

\section{Results}

Manipulation check. As expected, an ANOVA revealed significant differences in reported rivalry across conditions, $F(2,240)=120.29, p<.001$. Planned contrasts indicated that participants who described personal rivals reported significantly stronger rivalry ( $M=5.04$, $S D=1.39)$ than participants in the non-rival competition condition $(M=2.24, S D=1.24, t(240)$ $=13.30, p<.001)$ and the control condition $(M=2.19, S D=1.36, t(240)=13.65, p<.001)$. These latter two conditions did not differ significantly from one another $t(240)=.27, p=.79$.

Deception. To analyze use of deception, we first created a dichotomous variable indicating whether participants used some form of deception (categories $3-6$ ) or not (categories 1 and 2). A chi-square analysis indicated that there were significant differences among the three conditions, $\chi^{2}(2,240)=16.28, p<.001$. In support of our main hypothesis and shown in Figure 1, participants in the rivalry condition $(M=46.8 \%)$ were significantly more likely to employ deception than participants in the non-rival competition condition $\left(M=24.7 \% ; \chi^{2}(1,158)=\right.$ $8.55, p=.003)$, and participants in the control condition $\left(M=19.3 \% ; \chi^{2}(1,160)=13.96, p<\right.$ .001 ), which did not differ significantly from each other, $\left.\chi^{2}(1,164)=.71, p=.40\right)$.

Insert Figure 1 about here

We then looked more closely at the categories of deception employed (means by category and condition are shown in Table 3). Consistent with Study 2, there were no significant differences across condition in the frequency of lying directly, in numerical terms, $\chi^{2}(2,240)=$ 
$.65, p=.72$. However, there were significant differences across condition in the likelihood of using more indirect forms of deception (categories $4-6), \chi^{2}(2,240)=19.50, p<.001$. Participants in the rivalry condition $(M=30.3 \%)$ were more likely to employ indirect deception than were participants in the non-rival competition condition $\left(M=9.9 \% ; \chi^{2}(1,158)=10.51, p=\right.$ $.001)$ and control condition $\left(M=7.2 \% ; \chi^{2}(1,160)=14.38, p<.001\right)$.

Insert Table 3 about here

Unethical negotiation tactics. An ANOVA revealed significant differences in willingness to employ ethically questionable tactics across conditions, $F(2,240)=12.94, p<$ .001. Planned contrasts indicated that participants who imagined negotiating with a rival scored higher on the SINS scale $(M=3.35 ; S D=.99)$ than participants who imagined negotiating with a non-rival competitor $(M=2.89 ; S D=1.15 ; t(240)=2.85, p=.005, d=.43)$ and participants who imagined negotiating with an acquaintance $(M=2.53 ; S D=0.95 ; t(240)=5.08, p<.001, d$ $=.85)$. SINS scores were also higher in the non-rival competition condition than the control condition, $t(240)=2.22, p=.027, d=.34$.

Mediation. We next examined the psychological mechanisms underlying the observed positive effect of rivalry on intended unethical behavior. For these analyses, we restricted our comparison to the rivalry versus non-rival competition conditions, as this is the key distinction upon which this paper is focused. Participants in the rivalry condition reported significantly greater contingencies of self-worth based upon their performance vis-à-vis their recalled counterparts $\left(M_{\text {Rivalry }}=4.85\right.$ vs. $\left.M_{\text {Non-rival competition }}=3.40, t(158)=6.42, p<.001\right)$, status concerns $\left(M_{\text {Rivalry }}=4.71\right.$ vs. $\left.M_{\text {Non-rival competition }}=3.16, t(158)=7.89, p<.001\right)$, and performance orientations $\left(M_{\text {Rivalry }}=4.22\right.$ vs. $\left.M_{\text {Non-rival competition }}=3.38, t(158)=4.01, p<.001\right)$. All three of 
these factors also significantly predicted both dependent measures. There were no significant differences between the rivalry and non-rival competition conditions for perceptions of challenge, perceptions of threat, or mastery orientation (see Table 4 for correlations between measures). Thus, Hypothesis 5 was not supported.

Insert Table 4 about here

We began testing Hypotheses $2-4$ by running a set of simple mediation bootstrapping tests (Preacher \& Hayes, 2004; all bootstrapping mediation tests were run using the PROCESS macro in SPSS, Hayes, 2013), in which each of the three potential mediators was analyzed independently for both dependent measures. The indirect effect of rivalry on intended unethical behavior via contingency of self-worth was significant for SINS $(95 \%$ confidence interval $=$ $[.186, .403])$ but not for deception $(95 \%$ confidence interval $=[-.057, .420])$. Similarly, status concerns significantly mediated the effect of rivalry on SINS (95\% confidence interval $=[.154$, $.412]$ ) but not on deception (95\% confidence interval $=[-.072, .474])$. However, performance orientation served as a significant mediator for both SINS $(95 \%$ confidence interval $=[.369$, $.583])$ and deception $(95 \%$ confidence interval $=[.123, .665])$.

We then examined all three factors in simultaneous parallel mediation models (Hayes, 2013). For deception, performance orientation significantly mediated the effect of rivalry (95\% confidence interval $=[.076, .765])$, whereas status concerns $(95 \%$ confidence interval $=[-.341$, $.397])$ and contingency of self-worth $(95 \%$ confidence interval $=[-.405, .285])$ did not. Similarly, for SINS, performance orientation significantly mediated the effect of rivalry (95\% confidence interval $=[.298, .575])$, whereas status concerns $(95 \%$ confidence interval $=[-.140$, $.158])$ and contingency of self-worth $(95 \%$ confidence interval $=[-.087, .190])$ did not. The 
direct effects of rivalry on deception (95\% confidence interval $=[-.078, .1 .52])$ and SINS $(95 \%$ confidence interval $=[-.319, .340])$ were reduced to non-significance in both models.

These parallel mediation analyses suggest that an increased performance orientation serves as the primary mediating mechanism between rivalry and unethical behavior. As a final test, however, we examined the possibility of serial mediation (Hayes, 2013); specifically, the idea that rivalry fosters increased contingency of self-worth and/or status concerns, which in turn leads to an increased performance orientation, which in turn fosters greater unethicality. A serial mediation model for SINS indicated that the indirect effect of rivalry on unethicality through contingency of self-worth and performance orientation in serial was significant (95\% confidence interval $=[.122, .465])$. Similarly, the indirect effect of rivalry on unethicality through status concerns and performance orientation in serial was also significant $(95 \%$ confidence interval $=$ $[.020, .180])$. None of the indirect paths that included only a single mediator were significant, including the indirect effect of rivalry on unethicality via performance orientation only (95\% confidence interval $=[-.254, .085])$. Similar results were achieved for intended deception. The indirect effect of rivalry on intended deception through contingency of self-worth and performance orientation in serial was significant $(95 \%$ confidence interval $=[.041, .557])$, as was the indirect effect through status concerns and performance orientation in serial $(95 \%$ confidence interval $=[.016, .211])$. The indirect effect via performance orientation only was not significant $(95 \%$ confidence interval $=[-.278, .086])$. Thus, we have evidence of two serial mediation pathways from rivalry to unethical behavior, one via increased contingency of self-worth and performance orientation and the other via increased status concerns and performance orientation. Figure 2 displays this theoretical model.

Insert Figure 2 about here 


\section{Discussion}

Study 4 provided additional evidence for the positive effects of rivalry on unethical behavior as well as insight into the psychological mechanisms underlying these effects. Within a hypothetical negotiation scenario, participants employed greater deception and indicated a greater willingness to use unethical negotiation tactics when they imagined negotiating with a personal rival as compared to a non-rival competitor or acquaintance. Further, participants indicated that their performance vis-à-vis their rivals carried significantly greater weight in driving their sense of self-worth, that they were more concerned about their status relative to their rivals, and that the prospect of negotiating with a rival increased the extent to which they adopted a performance orientation. In a parallel mediation model, this last effect was found to be most responsible for the effects of rivalry on unethical behavior; however, serial mediation models indicated that the psychological pathway from rivalry to unethical behavior is more complex. It seems that rivalry increases contingency of self-worth and status concerns, both of which independently increase performance orientation, which then leads to greater unethicality.

\section{GENERAL DISCUSSION}

Despite substantial anecdotal evidence of its power to influence behavior, the topic of rivalry has received relatively little scientific scrutiny. In the current research, we compared rivalry to non-rival competition in terms of their consequences for unethical behavior. Across four studies, involving professional athletes, undergraduates, and adults from the general population, we observed that rivalry promoted greater unethical behavior than non-rival competition, independent of tangible stakes. This was true across multiple manipulations of rivalry and multiple measures of unethical behavior. These results are summarized in Table 5. 


\section{Insert Table 5 about here}

\section{Theoretical Contributions}

We believe that this research makes a number of theoretical contributions. First, we contribute in several ways to the burgeoning literature on rivalry. Existing research has linked rivalry to increased effort and motivation; our research explores the dark side of rivalry and suggests that it may also push individuals to pursue success in unethical ways, to a greater degree than general competition. Thus, rivalry may be a double-edged sword that merits careful management.

Our results from Study 4 also shed some light on the psychological experience of rivalry, how it differs from non-rival competition, and how this helps to explain the link between rivalry and unethical behavior. First, we observed that individuals viewed competitions against their rivals as more important to their sense of self-worth, and were more concerned about their status relative to their rivals, as compared to other competitions and competitors. Both of these findings help to illuminate the nature of the increased psychological stakes theorized to accompany rivalry (Kilduff, 2014; Kilduff et al., 2010), and underscore the idea that rivalry is fundamentally different from non-rival competition. Rather than simply mirroring competition with high tangible stakes, rivalry seems to be qualitatively different. This notion is supported by the fact that measures of tangible stakes in our studies did not relate to unethical behavior in the way that rivalry did. Competition against rivals appears to be uniquely important to our sense of sense of self and social standing, which may help to explain why it is so engaging and powerful.

Furthermore, we found that rivalry leads people to adopt a stronger performance orientation, that is, to focus more on performance approach goals. Within a given interaction, 
people may adopt a variety of goals (e.g., Dweck \& Leggett, 1988). Rivalry led people to focus more on winning and outperforming their opponents, and less on the means used to achieve these goals - including, apparently, ethicality - thus leading to greater unethical behavior. Mediation analyses depicted a model in which rivalry heightens psychological stakes, which leads to a greater performance orientation, which leads to greater unethicality.

In addition to shedding light on the psychological experience of rivalry and why it promotes unethical behavior, our findings link rivalry to existing literatures on contingency of self-worth (Crocker et al., 2003; Crocker \& Wolfe, 2001), status and status concerns (e.g., Anderson et al., 2001; Anderson et al., 2012; Blader \& Chen, 2011; Pettit, Yong, \& Spataro, 2010), and performance goals (Elliot \& Church, 1997; Elliot \& Harackiewicz, 1994; Midgley, Kaplan, \& Middleton, 2001; Tangirala, Kamdar, Venkataramani, \& Parke, 2013), which among other things, suggests a range of additional consequences to rivalry.

The second broad contribution of this research is in identifying rivalry as a previously unexplored determinant of unethical behavior, thus helping scholars to better understand when and why actors behave unethically. Further, by drawing upon existing research on the factors that contribute to rivalry (Kilduff, 2014; Kilduff et al., 2010), we are able to shed light on the conditions under which competition is generally more or less likely to lead to unethical behavior. That is, competition is more likely to foster unethical behavior when it entails repeated contests between similar or evenly-matched competitors, as compared to when it takes place between unfamiliar or anonymous ones.

Third, our findings highlight the importance of taking a relational approach to the study of both competition and unethical behavior. As discussed, competition has traditionally been modeled in objective, structural terms, but our results suggest that it can vary substantially 
depending on competitors' relationships. Seminal work on cooperation between organizations has demonstrated that accurate prediction of alliance formation requires taking into account past interactions and trust (Gulati, 1995); competition research is apt to benefit from a similar perspective. Similarly, research on unethical behavior has generally focused on the roles of individual and situational characteristics (e.g., Kish-Gephart et al., 2010). However, a small but growing body of work has begun to examine the importance of various relational factors (e.g., Gino, Ayal, \& Ariely, 2009; Gino \& Pierce, 2010; Mayer, Nurmohamed, Treviño, \& Schminke, 2013; Mayer, Tau, Workman, Van Dijke, \& De Cremer, 2012). For example, the relationship between leaders and their subordinates can substantially affect unethical behavior (Mayer et al., 2012). Our findings contribute to this new perspective and dovetail with a broader relational trend within organizational research, which has included topics such as job design (Grant, 2007), negotiations (Gelfand et al., 2006) and job attitudes (Wrzesniewski, Dutton, and Debebe, 2003).

\section{Organizational and Practical Implications}

Our findings also suggest a range of important organizational and practical implications. Competition is everywhere in the business world, and it often occurs between familiar and longstanding rivals. It is important to recognize that this may be a uniquely intense form of competition that varies substantially from anonymous 'perfect market' competition. Assuming that the two are the same could result in serious miscalculations and predictions about one's own, and one's opponents', behaviors. More specific to the findings documented here, unethical behavior is costly and destructive, and preventing it has become one of the primary applied goals of organizational research. Given the apparent role of rivalry in promoting unethical behavior, managers should carefully consider how organizational structures and policies may influence feelings of rivalry within employees. For instance, managers may want to design jobs, 
incentives, and promotion systems to avoid the antecedents of rivalry such as repeatedly pitting employees against each other, as many sales, legal, and financial firms are known to do. The upside may be increased motivation (Kilduff, 2014; Kilduff et al., 2010), but with significant downsides. Organizations might also be wary of placing too much emphasis on outperforming rival companies, lest this foster a culture of rivalry that prioritizes performance at the cost of ethical business practices. Managers should also be cognizant of their own propensity to be influenced by rivalry. Top management teams and boards of directors may want to take explicit measures to guard against rivalry influencing their strategic and moral judgments, such as relying on objective data and decision criteria, and soliciting the opinions of outsiders.

Overall, given its potential benefits and downsides, organizations are faced with important decisions about how to best manage rivalry. Future work should examine whether certain organizational factors, such as culture, incentives, and leadership, may allow organizations to harness the benefits of rivalry while simultaneously avoiding its downsides. The consequences of rivalry may also differ across different job settings and job characteristics. For instance, jobs for which performance is effort-based and autonomy is limited - thus limiting the opportunity for unethical behavior - may tend to benefit more from rivalry than jobs that offer freedom in decision-making or center around functions for which unethicality is a concern. Exploring the conditions under which rivalry is generally beneficial versus harmful constitutes an important next step for this research.

\section{Future Directions}

There are a number of additional potential avenues for future research on rivalry. First, future work should examine unethical behavior at the organizational level. Although Studies 1 and 2 examined rivalry between organizations, these were not traditional for-profit businesses, 
and the unethical behavior was perpetrated by individuals. Theoretically, there is reason to believe that our results will generalize to organizations - a range of organizational outcomes have been successfully predicted by psychological theories that treat the organization as an individual (e.g., Cyert \& March, 1963; Greve, 1998; Zajac \& Bazerman, 1991), and the strategy, structure, and culture of organizations are often determined by a few key individuals in positions of power (Cho \& Hambrick, 2006; Hayward \& Hambrick, 1997; Kaplan, 2011; Miller \& Dröge, 1986; Staw \& Sutton, 1992). Future research, however, should investigate this empirically - for instance, examining the role of rivalry in promoting accounting fraud. In such research, interfirm rivalry might be measured via surveys of industry experts, text analysis of media reports, or measures that tap into the antecedents of rivalry, such as repeated competition (e.g., tenure in the same industry). To control for more objective competitive pressures and stakes, one could collect measures of market overlap and resource similarity (Chen, 1996).

Second, research should explore the range of unethical behaviors affected by rivalry, and whether it increases certain types more than others. In Studies 3 and 4, we observed that rivalry increased participants' use of indirect forms of deception, but not the extent to which they lied in concrete, numerical, terms. However, in Study 2, we found that rivalry did lead to the use of direct, unambiguous deception. It is possible that these findings are the result of differences in study context. Study 2 involved an organizational rivalry and a one-shot decision game, whereas Studies 3 and 4 examined individual-level rivalry in the context of a negotiation; future work should examine these possibilities. More generally, in this research we examined forms of unethical behavior that were specifically directed at one's rival, as well as behavior that can be, at least loosely, classified as furthering performance (that rivalry increased this kind of unethical behavior is consistent with our finding that it invokes a performance orientation). Future work 
should explore whether rivalry affects other types of unethical behavior. In particular, it would be very interesting to explore whether rivalry exhibits any evidence of a 'carryover' effect (Sassenberg, Moskowitz, Jacoby, \& Hansen, 2007), such that the experience of competing against a rival might promote greater unethical behavior even in domains outside of the rivalry itself, due to the mindset activated by rivalry. For example, negotiating with a rival might activate a performance orientation that carries over to a subsequent negotiation with a non-rival. Or perhaps athletes, and even their fans, behave more unethically following matches against rival teams. It would also be interesting to see whether exposure to rivalry could affect unethical behavior less connected to performance goals - for example, using company supplies for personal purposes or downloading software illegally (e.g., Detert, Treviño, \& Sweitzer, 2008).

Third, research should continue to explore the psychological underpinnings of rivalry and its effects on unethical behavior. In particular, the "hot" side of rivalry would seem a fruitful avenue for research. This could include a more complete investigation into both the affective and physiological profiles of rivalry. As mentioned, there is some initial evidence that rivalry promotes heightened testosterone as compared to non-rival competition (Neave \& Wolfson, 2003) - future work could build upon this by examining additional hormones, cardiovascular responses, and even brain activity. Doing so would shed additional light on the experience of rivalry and also provide a better test for the potential roles of challenge and threat responses. Related work might also more directly compare rivalry to other forms of competition with heightened stakes. This could include competition with high tangible stakes, and competition with high psychological stakes, perhaps due to heightened status concerns (e.g., competitors of proximal rank) or contingency of self-worth (e.g., tasks that are identity-relevant). Future research should also delve deeper into the deliberative versus automatic nature of rivalry's 
effects on unethical behavior. Scholars are increasingly realizing that ethical decisions are a product of both deliberative and automatic processes, and the extent to which each cognitive system is active depends on a wide range of factors (Moore \& Gino, 2015). A related question is whether rivalry might even alter individuals' awareness of whether a given behavior or decision has an ethical component, perhaps by shifting decision frames (Tenbrunsel \& Messick, 1999) or creating a kind of performance-focused tunnel vision (Moore \& Gino, 2015. It is also possible that people might have an easier time rationalizing unethical behavior within the context of rivalry; perhaps "all is fair in love and rivalry."

Fourth, research should explore additional consequences of rivalry besides motivation and unethical behavior. By increasing status concerns, contingency of self-worth, and performance orientation independent of tangible stakes, rivalry could lead to a range of important behaviors, many of which might be suboptimal. First, actors might be more likely to focus on relative performance as opposed to absolute performance when competing against their rivals that is, adopt a 'competitive' social value orientation (Messick \& McClintock, 1968). In turn, they may be willing to sacrifice their own gains in order to limit those of a rival. In a related vein, actors might be unwilling to cooperate with their rivals (e.g., pursue joint ventures) even when it is beneficial to do so. Second, rivalry might create such a strong reluctance to concede defeat that competing actors escalate commitment to losing competitive endeavors instead of abandoning them (e.g., Staw, 1976). For instance, rival firms might continue investing in underperforming product lines rather than cutting their losses and exiting the market. Third, given conditions of limited attention and cognitive resources (e.g., Cyert \& March, 1963), actors engaged in fierce rivalries might overlook non-rival competitors. In other words, rivalry could lead to a form of tunnel vision or myopia in which actors are so preoccupied with their rivals that 
they become vulnerable to other competitive threats. Fourth, the observed link between rivalry and status concerns suggests that rivalry might lead to increased conspicuous consumption (Miller, 2009; Rucker \& Galinsky, 2008; Sivanathan \& Pettit, 2010), and, if rivals are placed upon the same team, increased status conflict (Bendersky \& Hays, 2012).

Finally, future research could explore whether certain interventions can diminish or extinguish rivalry or its unwanted consequences. For example, perhaps cooperation amongst rivals, even if forced upon them by authorities or regulatory bodies, could diminish the rivalry between them (e.g., Sherif, Harvey, White, Hood, \& Sherif, 1961). Another, individual-level intervention that could work might be self-affirmation. Numerous studies show that allowing individuals to affirm their sense of self can reduce a host of biases (Sherman \& Cohen, 2006), and given our results showing that rivalry invokes increased status concerns and contingency of self-worth, interventions that mitigate such concerns may also mitigate the power of rivalry to affect behavior. Besides self-affirmation, providing individuals with admiration and respect might also limit the effects of rivalry by mitigating status concerns. Future work could directly manipulate these factors and others that may that shift participants' goals and objectives in competition away from relative performance; examining such moderators would a) provide greater evidence for the mechanisms that link rivalry to unethical behavior and b) highlight potential ways of preventing rivalry from becoming harmful. Further, although in Study 2 we found that the effects of rivalry on unethical behavior did not vary by participants' feelings of dislike towards their counterparts, future work could conduct a more thorough investigation of the interplay between rivalry and dislike, and whether there are any important differences between liked or respected rivals and disliked rivals.

\section{Conclusion}


Competition is ubiquitous, among individuals, groups, and organizations. When competing, actors face a variety of decisions about how to behave, how to compete, and how to attempt to increase their chances of victory. The relationships, and in particular the rivalries, that exist between actors can affect these decisions. Our work suggests that actors who feel rivalry are more likely to engage in the kind of behavior that has come to define the ugly side of competition, such as deception, cheating, and sabotage. These results paint rivalry as a powerful motivational and corruptive force with significant implications for organizations. 


\section{References}

Anderman, E. M., Griesinger, T., \& Westerfield, G. 1998. Motivation and cheating during early adolescence. Journal of Educational Psychology, 90(1): 84-93.

Anderman, E. M., \& Midgley, C. 2004. Changes in self-reported academic cheating across the transition from middle school to high school. Contemporary Educational Psychology, 29(4): 499-517.

Anderson, C., John, O. P., Keltner, D., \& Kring, A. M. 2001. Who attains social status? Effects of personality and physical attractiveness in social groups. Journal of Personality and Social Psychology, 81(1): 116-132.

Anderson, C., Kraus, M. W., Galinsky, A. D., \& Keltner, D. 2012. The local-ladder effect: Social status and subjective well-being. Psychological Science, 23: 764-771.

Ash, E. 2001. Purple virtues: A leadership cure for unhealthy rivalry. Aerospace Power Journal, 15: 32-39.

Barkow, J. H. 1975. Prestige and Culture - Biosocial Interpretation. Current Anthropology, 16(4): 553-572.

Baum, J. A. C. \& Korn, H. J. 1996. Competitive dynamics of interfirm rivalry. Academy of Management Journal, 39: 255-291.

Baum, J. A. C., \& Korn, H. J. 1999. Dynamics of dyadic competitive interaction. Strategic Management Journal, 20: 251-278.

Becker, G. S. 1968. Crime and punishment: Economic approach. Journal of Political Economy, 76(2): 169-217.

Beersma, B., Hollenbeck, J. R., Humphrey, S. E., Moon, H., \& Conlon, D. E. 2003. Cooperation, competition, and team performance: Toward a contingency approach. Academy of Management Journal, 46: 572-590.

Blader, S. L., \& Chen, Y.-R. 2011. What influences how higher-status people respond to lowerstatus others? Effects of procedural fairness, outcome favorability, and concerns about status. Organization Science, 22(4): 1040-1060.

Bothner, M. S., Kang, J. H., \& Stuart, T. E. 2007. Competitive crowding and risk taking in a tournament: Evidence from NASCAR racing. Administrative Science Quarterly, 52: 208-247.

Brehm, J. W., Wright, R. A., Solomon, S., Silka, L., \& Greenberg, J. 1983. Perceived difficulty, energization, and the magnitude of goal valence. Journal of Experimental Social Psychology, 19, 21-48.

Brickman, P., Redfield, J., Crandall, R., \& Harrison, A. A. 1972. Drive and predisposition as factors in attitudinal effects of mere exposure. Journal of Experimental Social Psychology, 8: 31-44.

Buhrmester, M. D., Kwang, T., \& Gosling, S. D. 2011. Amazon's Mechanical Turk: A new source of inexpensive, yet high-quality data? Perspectives on Psychological Science, 6: 3-5.

Chen, M.-J. 1996. Competitor analysis and interfirm rivalry: Toward a theoretical integration. Academy of Management Review, 21: 100-134.

Cho, T. S., \& Hambrick, D. C. 2006. Attention as the mediator between top management team characteristics and strategic change: The case of airline deregulation. Organization Science, 17: 453-469.

Cyert, R., \& March, J. 1963. Behavioral Theory of the Firm. Oxford: Blackwell. 
De Waal, F. 1992. Chimpanzee politics: Sex and power among apes. London, UK: Jonathan Cape.

Deci, E. L., Betley, G., Kahle, J., Abrams, L., \& Porac, J. 1981. When trying to win: Competition and intrinsic motivation. Personality and Social Psychology Bulletin, 7: 7983.

DePalma, M. T., Madey, S. F., \& Bornschein, S. 1995. Individual differences and cheating behavior: Guilt and cheating in competitive situations. Personality and Individual Differences, 18(6): 761-769.

Detert, J. R., Treviño, L. K., \& Sweitzer, V. L. 2008. Moral disengagement in ethical decision making: a study of antecedents and outcomes. Journal of Applied Psychology, 93: 374391.

Deutsch, M. 1949. A theory of cooperation and competition. Human Relations, 2: 129-152.

Eccles, J. S. 1983. Expectancies, values, and academic choice: Origins and changes. San Francisco: Freeman.

Eisenberger, R., \& Shank, D. M. 1985. Personal work-ethic and effort training affect cheating. Journal of Personality and Social Psychology, 49(2): 520-528.

Ellis, L. 1994. Social stratification and socioeconomic inequality Vol. 2: Reproductive and interpersonal aspects of dominance and status: Westport, $\mathrm{CN}$ : Praeger.

Elsbach, K. D., \& Battacharya, C. B. 2001. Defining who you are by what you're not: Organizational disidentification and the national rifle association. Organization Science, 12: 393-413.

Ferrier, W. J. 2001. Navigating the competitive landscape: The drivers and consequences of competitive aggressiveness. Academy of Management Journal, 44: 858-877.

Festinger, L. 1954. A theory of social comparison processes. Human Relations, 7: 117-140.

Flamigni, P.1995. Il derby delle parole. Genova: Erga.

Garcia, S. M., Tor, A., \& Gonzalez, R. 2006. Ranks and rivals: A theory of competition. Personality and Social Psychology Bulletin, 32: 970-982.

Gelfand, M. J., Smith, V., Raver, J., Nishii, L. \& O'Brien, K. 2006. Negotiating relationally: The dynamics of the relational self in negotiations. Academy of Management Review, 31: 427-45.

Gino, F., Ayal, S., \& Ariely, D. 2009. Contagion and differentiation in unethical behavior: The effect of one bad apple on the barrel. Psychological Science, 20(3): 393-398.

Gino, F., \& Pierce, L. 2010. Robin Hood under the hood: Wealth-based discrimination in illict customer help. Organization Science, 21(6): 1176-1194.

Goertz, G., \& Diehl, P. F. 1993. Enduring rivalries: Theoretical constructs and empirical patterns. International Studies Quarterly, 37: 147-171.

Grant, A. M. 2007. Relational job design and the motivation to make a prosocial difference. Academy of Management Review, 32: 393-417.

Gregory, M. 1994. Dirty Tricks: Inside story of British Airways' secret war against Richard Branson's Virgin Atlantic. New York: Little, Brown.

Greve, H. R. 1998. Performance, aspirations, and risky organizational change. Administrative Science Quarterly, 43: 58-86.

Greve, H. R., Palmer, D., \& Pozner, J. E. 2010. Organizations gone wild: The causes, processes, and consequences of organizational misconduct. Academy of Management Annals, 4: 53-107. 
Gulati, R.1995. Does familiarity breed trust? The implications of repeated ties for contractual choice in alliances. Academy of Management Journal, 38: 85-112.

Haidt, J. 2001. The emotional dog and its rational tail: A social intuitionist approach to moral judgment. Psychological Review, 108(4): 814-834.

Hayward, M. L. A., \& Hambrick, D. C. 1997. Explaining the premiums paid for large acquisitions: Evidence of CEO hubris. Administrative Science Quarterly, 42: 103-127.

Hegarty, W. H., \& Sims, H. P. 1978. Some determinants of unethical decision behavior: An experiment. Journal of Applied Psychology, 63(4): 451-457.

Hershfield, H. E., Cohen, T. R., \& Thompson, L. 2012. Short horizons and tempting situations: Lack of continuity to our future selves leads to unethical decision making and behavior. Organizational Behavior and Human Decision Processes, 117: 298-310.

Kahneman, D., \& Miller, D.T. 1986. Norm theory: Comparing reality to its alternatives. Psychological Review, 93, 136-153.

Kaplan, S. 2011. Research in cognition and strategy: Reflections on two decades of progress and a look to the future. Journal of Management Studies, 48(3): 665-695.

Karpoff, J. M., Lee, D. S., \& Vendrzyk, V. P. 1999. Defense procurement fraud, penalties, and contractor influence. Journal of Political Economy, 107(4): 809-842.

Katila, R., \& Chen, E. L. 2008. Effects of search timing on innovation: The value of not being in sync with rivals. Administrative Science Quarterly, 53: 593-625.

Kern, M. C., \& Chugh, D. 2009. Bounded ethicality: The perils of loss framing. Psychological Science, 20: 378-384.

Kilduff, G. J. 2014. Driven to win: Rivalry, motivation, and performance. Social Psychological and Personality Science. In press.

Kilduff, G. J., Elfenbein, H. A., \& Staw, B. M. 2010. The psychology of rivalry: A relationallydependent analysis of competition. Academy of Management Journal, 53: 943-969.

Kish-Gephart, J. J., Harrison, D. A., \& Treviño, L. K. 2010. Bad apples, bad cases and bad barrels: Meta-analytic evidence about sources of unethical decisions at work. Journal of Applied Psychology, 95(1): 1-31.

Kohn, A. 1992. No contest: The case against competition. New York: Houghton Mifflin Company.

Kreps, D. M., \& Wilson, R. 1982. Reputation and imperfect information. Journal of Economic Theory, 27(2): 253-279.

Ku, G., Malhotra, D., \& Murnighan, J. K. 2005. Towards a competitive arousal model of decision-making: A study of auction fever in live and Internet auctions. Organizational Behavior and Human Decision Processes, 96: 89-103.

Lewicki, R. J. 1983. Lying and deception: A behavioral model. In M. H. B. R. J. Lewicki (Ed.), Negotiating in organizations: 68-90. Beverly Hills, CA: Sage.

Liening, S. H., Mehta, P. H., \& Josephs, R. A. 2012. Competition. To appear in V. S. Ramachandran (ed.), Encyclopedia of Human Behavior. San Diego, CA: Academic Press.

Locke, K. D. 2007. Personalized and generalized comparisons: Causes and consequences of variations in the focus of social comparisons. Personality and Social Psychology Bulletin, 33: 213-225.

Magee, J. C., \& Galinsky, A., D. 2008. Social Hierarchy: The self-reinforcing nature of power and status. The Academy of Management Annals, 2(1): 351-398.

Malhotra, D. 2010. The desire to win: The effects of competitive arousal on motivation and 
performance. Organizational Behavior and Human Decisions Processes, 111: 139-146.

Mayer, D. M., Kuenzi, M., Greenbaum, R., Bardes, M., \& Salvador, R. 2009. How low does ethical leadership flow? Test of a trickle-down model. Organizational Behavior and Human Decision Processes, 108(1): 1-13.

Mayer, D. M., Nurmohamed, S., Treviño, L. K., Shapiro, D. L., \& Schminke, M. 2013. Encouraging employees to report unethical conduct internally: It takes a village. Organizational Behavior and Human Decision Processes, 121(1): 89-103.

Medvec, V. H., Madey, S., \& Gilovich, T. 1995. When less is more: Counterfactual thinking and satisfaction among Olympic medal winners. Journal of Personality and Social Psychology, 69: 603-610.

Medvec, V. H., \& Savitsky, K. 1997. When doing better means feeling worse: The effects of categorical cutoff points on counterfactual thinking and satisfaction. Journal of Personality and Social Psychology, 72: 1284-1296.

Messick, D. M., \& McClintock, C. G.1968. Motivational bases of choice in experimental games. Journal of Experimental Social Psychology, 4: 1-25.

Midgley, C., Kaplan, A., \& Middleton, M. 2001. Performance-approach goals: Good for what, for whom, under what circumstances, and at what cost?.Journal of Educational Psychology, 93: 77-86.

Miller, D., \& Droge, C. 1986. Psychological and traditional determinants of structure. Administrative Science Quarterly, 31(4): 539-560.

Miller, G. 2009. Spent: Sex, evolution, and consumer behavior. New York: Viking.

Moore, C., Detert, J. R., Treviño, L. K., Baker, V. L., \& Mayer, D. M. 2012. Why employees do bad things: Moral disengagement and unethical organizational behavior. Personnel Psychology, 65(1): 1-48.

Moore, C., \& Gino F. 2015. Approach, Ability, Aftermath: A Psychological Framework of Unethical Behavior at Work. Academy of Management Annals, 9. In press.

Murdock, T. B., Hale, N. M., \& Weber, M. J. 2001. Predictors of cheating among early adolescents: Academic and social motivations. Contemporary Educational Psychology, 26(1): 96-115.

Neave, N., \& Wolfson, S. 2003. Testosterone, territoriality, and the 'home advantage'. Physiology \& Behavior, 78: 269-275.

Perry, A. R., Kane, K. M., Bernesser, K. J., \& Spicker, P. T. 1990. Type-A behavior, competitive achievement-striving, and cheating among college students. Psychological Reports, 66(2): 459-465.

Pettit, N. C. 2012. The dysfunctional side of status: Status distance and change as determinants of damaging intragroup behavior. Paper presented at the Academy of Management Annual Meeting in Boston, MA.

Pettit, N. C., Yong, K., \& Spataro, S. E. 2010. Holding your place: Reactions to the prospect of status gains and losses. Journal of Experimental Social Psychology, 46(2): 396-401.

Porter, M. E. 1980. Competitive strategy. New York: Free Press.

Preacher, K. J., \& Hayes A. F. 2004. SPSS and SAS procedures for estimating indirect effects in simple mediation models. Behavior Research Methods, Instruments, \& Computers, 36: 717-731.

Reynolds, S. J. 2006. A neurocognitive model of the ethical decision-making process: Implications for study and practice. Journal of Applied Psychology, 91: 737-748. 
Reynolds, S. J., \& Ceranic, T. L. 2007. The effects of moral judgment and moral identity on moral behavior: An empirical examination of the moral individual. Journal of Applied Psychology, 92(6): 1610-1624.

Robinson, J. R., Lewicki, R. J., \& Donahue E. M. (2000). Extending and testing a five factor model of ethical and unethical bargaining tactics: Introducing the SINS scale. Journal of Organizational Behavior, 21: 649-664.

Ronay, R., \& Galinsky, A. D. 2011. Lex Talionis: Testosterone and the law of retaliation. Journal of Experimental Social Psychology, 47: 702-705.

Rucker, D. D., \& Galinsky, A. D. 2008. Desire to acquire: Powerlessness and compensatory consumption. Journal of Consumer Research, 35: 257-267.

Sassenberg, K., Moskowitz, G. B., Jacoby, J., \& Hansen, N. 2007. The carry-over effect of competition: The impact of competition on prejudice towards uninvolved outgroups. Journal of Experimental Social Psychology, 43: 529-538.

Scherer, F. M., \& Ross, S. 1990. Industrial market structure and economic performance (3rd ed.). Boston: Houghton Mifflin.

Schultheiss, O. C., \& Rohde, W. Implicit power motivation predicts men's testosterone changes and implicit learning in a contest situation. Hormones and Behavior, 41(2): 195-202.

Schweitzer, M. E., DeChurch, L. A., \& Gibson, D. E. 2005. Conflict Frames and the Use of Deception: Are Competitive Negotiators Less Ethical? Journal of Applied Social Psychology, 35: 2123-2149.

Schwepker, C. H., Jr. 1999. Understanding salespeople's intention to behave unethically: The effects of perceived competitive intensity, cognitive moral development and moral judgment. Journal of Business Ethics, 21(4): 303.

Scott, W. E., \& Cherrington, D. J. 1974. Effects of competitive, cooperative, and individualistic reinforcement contingencies. Journal of Personality and Social Psychology, 30: 748758.

Sherif, M., Harvey, O. J., White, B. J., Hood, W. R., \& Sherif, C. W. 1961. Intergroup cooperation and competition: The Robbers Cave experiment. Norman, OK: University Book Exchange.

Sherman, D. K., \& Cohen, G. L. 2006. The psychology of self-defense: Self-affirmation theory. Advances in experimental social psychology, 38: 183-242.

Sivanathan, N., Pettit., N. C. 2010. Protecting the self through consumption: Status goods as affirmational commodities. Journal of Experimental Social Psychology, 46: 564-570.

Staw, B. M. 1976. Knee Deep in the Big Muddy. Organizational Behavior and Human Decision Process, 35: 124-140.

Staw, B. M., \& Hoang, H. 1995. Sunk costs in the NBA: Why draft order affects playing time and survival in professional basketball. Administrative Science Quarterly, 40: 474-494.

Staw, B. M., \& Sutton, R. I. 1992. Macro organizational psychology. In J. K. Murnighan (Ed.), Social psychology in organizations: Advances in theory and research: $350-384$. Englewood Cliffs, NJ: Prentice Hall.

Stinnett, D. M., \& Diehl, P. F. 2001. The path(s) to rivalry: Behavioral and structural explanations of rivalry development. Journal of Politics, 63: 717-740.

Sunstein, C. R. 2005. Moral heuristics. Behavioral and Brain Sciences, 28(4): 531-541.

Tauer, J. M., \& Harackiewicz, J. M. 1999. Winning isn't everything: Competition, achievement orientation, and intrinsic motivation. Journal of Experimental Social Psychology, 35: 209-238. 
Tenbrunsel, A. E., \& Messick, D. M. 1999. Sanctioning systems, decision frames, and cooperation. Administrative Science Quarterly, 44(4): 684-707.

Tesser, A. 1988. Toward a self-evaluation maintenance model of social behavior. In L. Berkowitz (Ed.), Advances in experimental social psychology, 21: 181-227. New York: Academic Press.

Thompson, W. R. 1995. Principal Rivalries. Journal of Conflict Resolution, 39: 195-223.

Treviño, L. K., Weaver, G. R., \& Reynolds, S. J. 2006. Behavioral ethics in organizations: A review. Journal of Management, 32(6): 951-990.

Vaughan, D. 1999. The dark side of organizations: Mistake, misconduct, and disaster. Annual Review of Sociology, 25: 271-305.

Wankel, L. M. 1972. Competition in motor performance: An experimental analysis of motivational components. Journal of Experimental Social Psychology, 8(5): 427-437.

Whitley, B. E. 1998. Factors associated with cheating among college students: A review. Research in Higher Education, 39(3): 235-274.

White, M. 2001. Acid tongues and tranquil dreamers: Eight scientific rivalries that changed the world. New York: HarperCollins.

Wigfield, A., \& Eccles, J. S. 1992. The development of achievement task values: A theoretical analysis. Developmental Review, 12(3): 265-310.

Wrzesniewski, A. C., Dutton, J. E., \& Debebe, G.. 2003. Interpersonal sensemaking and the meaning of work. Research in Organizational Behavior, 25: 93-135.

Zajac, E. J., \& Bazerman, M. H. 1991. Blind spots in industry and competitor analysis: Implications of interfirm (mis)perceptions for strategic decisions. Academy of Management Review, 16(1): 37-56.

Zajonc, R. B. 1968. Attitudinal effects of mere exposure. Journal of Personality and Social Psychology, 9: 1-27.

Zhong, C., Phillips, K. W., Leonardelli, G. J., \& Galinsky A. D. 2008. Negational categorization and intergroup behavior. Personality and Social Psychology Bulletin, 34: 793-806. 
TABLE 1

Study 1 correlations between match-level variables

\begin{tabular}{|c|c|c|c|c|c|c|c|c|c|c|c|c|}
\hline & Variable & 1 & 2 & 3 & 4 & 5 & 6 & 7 & 8 & 9 & 10 & 11 \\
\hline 1. & Yellow cards & & & & & & & & & & & \\
\hline 2. & Red cards & $.18 * * *$ & & & & & & & & & & \\
\hline 3. & Rivalry ( 0 or 1$)$ & $.12 * * *$ & $.04 \dagger$ & & & & & & & & & \\
\hline 4. & Proximity in standings & $.09 * * *$ & $.05^{*}$ & .00 & & & & & & & & \\
\hline 5. & $\begin{array}{l}\text { Similarity in recent } \\
\text { performance }\end{array}$ & .01 & -.02 & .00 & $.29 * * *$ & & & & & & & \\
\hline 6. & Mid-season ( 0 or 1$)$ & .01 & -.02 & $-.04 \dagger$ & $-.06 * *$ & $-.10 * * *$ & & & & & & \\
\hline 7. & Late-season ( 0 or 1$)$ & $-.06 * *$ & -.01 & -.02 & $.38 * * *$ & .00 & $-.48 * * *$ & & & & & \\
\hline 8. & Attendance (in thousands) & $-.06 * *$ & $-.04 *$ & $.27 * * *$ & $.13 * * *$ & $-.05 *$ & -.03 & .02 & & & & \\
\hline 9. & No crowd $(0$ or 1$)$ & -.00 & -.00 & -.01 & -.03 & $-.05 *$ & $.04 *$ & -.02 & $.12 * * *$ & & & \\
\hline 10. & Goal differential & $-.13 * * *$ & .03 & -.01 & $-.05 * *$ & $-.04 *$ & .01 & -.03 & $.11 * * *$ & -.01 & & \\
\hline 11. & $\begin{array}{l}\text { Avg. \# of yellow cards given } \\
\text { by referee }\end{array}$ & $.14 * * *$ & .02 & $.04 *$ & $-.06 * *$ & $-.05 * *$ & $.03 \dagger$ & $.07 * * *$ & $.06^{* *}$ & -.00 & $.04 \dagger$ & \\
\hline 12. & $\begin{array}{l}\text { Avg. \# of red cards given by } \\
\text { referee }\end{array}$ & $.05^{*}$ & -.01 & .01 & -.02 & $-.03 \dagger$ & .02 & .02 & -.00 & .00 & .02 & $.41 * * *$ \\
\hline
\end{tabular}

Note: $\mathrm{n}=2788 ; \dagger \mathrm{p} \leq .10 ; * \mathrm{p} \leq .05 ; * * \mathrm{p} \leq .01 ; * * * \mathrm{p} \leq .001$, two-tailed tests. 
TABLE 2

Study 1 Poisson regression analysis models of yellow and red cards

\begin{tabular}{lll}
\hline Variable & Yellow cards & Red cards \\
\hline Rivalry (0 or 1) & $0.41^{* * *}$ & $0.64^{* *}$ \\
Proximity in standings & $(0.06)$ & $(0.23)$ \\
& $0.00^{*}$ & $0.01^{*}$ \\
Similarity in recent performance & $(0.00)$ & $(.00)$ \\
& -0.00 & $-.03 \dagger$ \\
Mid-season (0 or 1) & $(0.01)$ & $(.02)$ \\
& -0.01 & -0.05 \\
Late-season (0 or 1) & $(0.02)$ & $(.08)$ \\
& $-0.06^{*}$ & 0.03 \\
Attendance (in thousands) & $(0.03)$ & $(0.09)$ \\
& $-0.00^{* * *}$ & $-0.01 * *$ \\
No crowd (0 or 1) & $(0.00)$ & $(0.00)$ \\
Goal differential & -0.07 & -0.21 \\
& $(0.11)$ & $(0.41)$ \\
Avg. \# of cards given by referee & $-0.06^{* * *}$ & $0.06^{*}$ \\
& $(0.01)$ & $(0.03)$ \\
Log likelihood & $0.08^{* * *}$ & -0.08 \\
Likelihood ratio $\chi^{2}$ & $(0.01)$ & $(0.17)$ \\
\hline
\end{tabular}

Note: $\mathrm{n}=2788 ; \uparrow \mathrm{p} \leq .10 ; * \mathrm{p} \leq .05 ; * * \mathrm{p} \leq .01 ; * * * \mathrm{p} \leq .001$, two-tailed tests.

Standard errors are in parentheses.

TABLE 3

Study 4 categories of opening statements by condition

\begin{tabular}{llll}
\hline & Control & Competition & Rivalry \\
\hline Told the complete truth & $43.4 \%$ & $43.2 \%$ & $15.2 \%$ \\
Did not mention offer or amount & $37.3 \%$ & $32.1 \%$ & $38.0 \%$ \\
Lied in numerical terms & $12.0 \%$ & $14.8 \%$ & $16.5 \%$ \\
Lied in words & $1.2 \%$ & $0.0 \%$ & $7.6 \%$ \\
Exaggerated & $2.4 \%$ & $6.2 \%$ & $12.7 \%$ \\
Indicated having multiple offers & $3.6 \%$ & $3.7 \%$ & $10.1 \%$ \\
\hline
\end{tabular}


TABLE 4

Study 4 correlations

\begin{tabular}{|c|c|c|c|c|c|c|c|c|c|}
\hline & Variable & 1 & 2 & 3 & 4 & 5 & 6 & 7 & 8 \\
\hline 1. & Rivalry ( 0 or 1$)$ & & & & & & & & \\
\hline 2. & Deception & $.23 * *$ & & & & & & & \\
\hline 3. & SINS & $.21 * *$ & $.40 * * *$ & & & & & & \\
\hline 4. & Contingency of self-worth & $.46 * * *$ & $.26 * * *$ & $.51 * * *$ & & & & & \\
\hline 5. & Status concerns & $.53 * * *$ & $.240 * * *$ & $.45 * * *$ & $.72 * * *$ & & & & \\
\hline 6. & Performance goals & $.31 * * *$ & $.32 * * *$ & $.65 * * *$ & $.69 * * *$ & $.61 * * *$ & & & \\
\hline 7. & Mastery goals & -.06 & $.16^{*}$ & $.41 * * *$ & $.29 * * *$ & $.23 * * *$ & $.45 * * *$ & & \\
\hline 8. & Challenge & .09 & .10 & $.38 * * *$ & $.28 * * *$ & $.17 * *$ & $.39 * * *$ & $.48 * * *$ & \\
\hline 9. & Threat & .05 & .01 & $.16^{*}$ & $.20 * *$ & $.24 * * *$ & $.22 * *$ & .10 & .05 \\
\hline
\end{tabular}

Note: $\mathrm{n}=243 ; * \mathrm{p} \leq .05 ; * * \mathrm{p} \leq .01 ; * * * \mathrm{p} \leq .001$, two-tailed tests.

TABLE 5

Rivalry vs. non-rival competition: Summary of findings

\begin{tabular}{|c|c|c|c|c|c|c|}
\hline & $\begin{array}{l}\text { Study } 1 \\
\text { Yellow cards }\end{array}$ & $\begin{array}{l}\text { Study } 1 \\
\text { Red cards }\end{array}$ & $\begin{array}{l}\text { Study } 2 \\
\text { Deception }\end{array}$ & $\begin{array}{l}\text { Study } 3 \\
\text { Deception } \\
\end{array}$ & $\begin{array}{l}\text { Study } 4 \\
\text { Deception }\end{array}$ & $\begin{array}{l}\text { Study } 4 \\
\text { SINS }\end{array}$ \\
\hline Non-rival competition & $4.25(1.95)$ & $0.33(0.60)$ & $12.2 \%$ & $32.7 \%$ & $24.7 \%$ & $2.89(1.15)$ \\
\hline Rivalry & $6.02(1.99)$ & $0.50(0.96)$ & $50 \%$ & $56.4 \%$ & $46.8 \%$ & $3.35(.99)$ \\
\hline Test of difference in means & $t=6.12 * * *$ & $t=1.90 \dagger$ & $\chi^{2}=11.21 * *$ & $\chi^{2}=5.00 *$ & $\chi^{2}=8.55^{* *}$ & $t=2.85 * *$ \\
\hline
\end{tabular}

Note: $* \mathrm{p} \leq .05 ; * * \mathrm{p} \leq .01 ; * * * \mathrm{p} \leq .001$, two-tailed tests.

Means by condition are displayed; standard deviations are in parentheses. 
FIGURE 1

Study 4 use of deception by condition

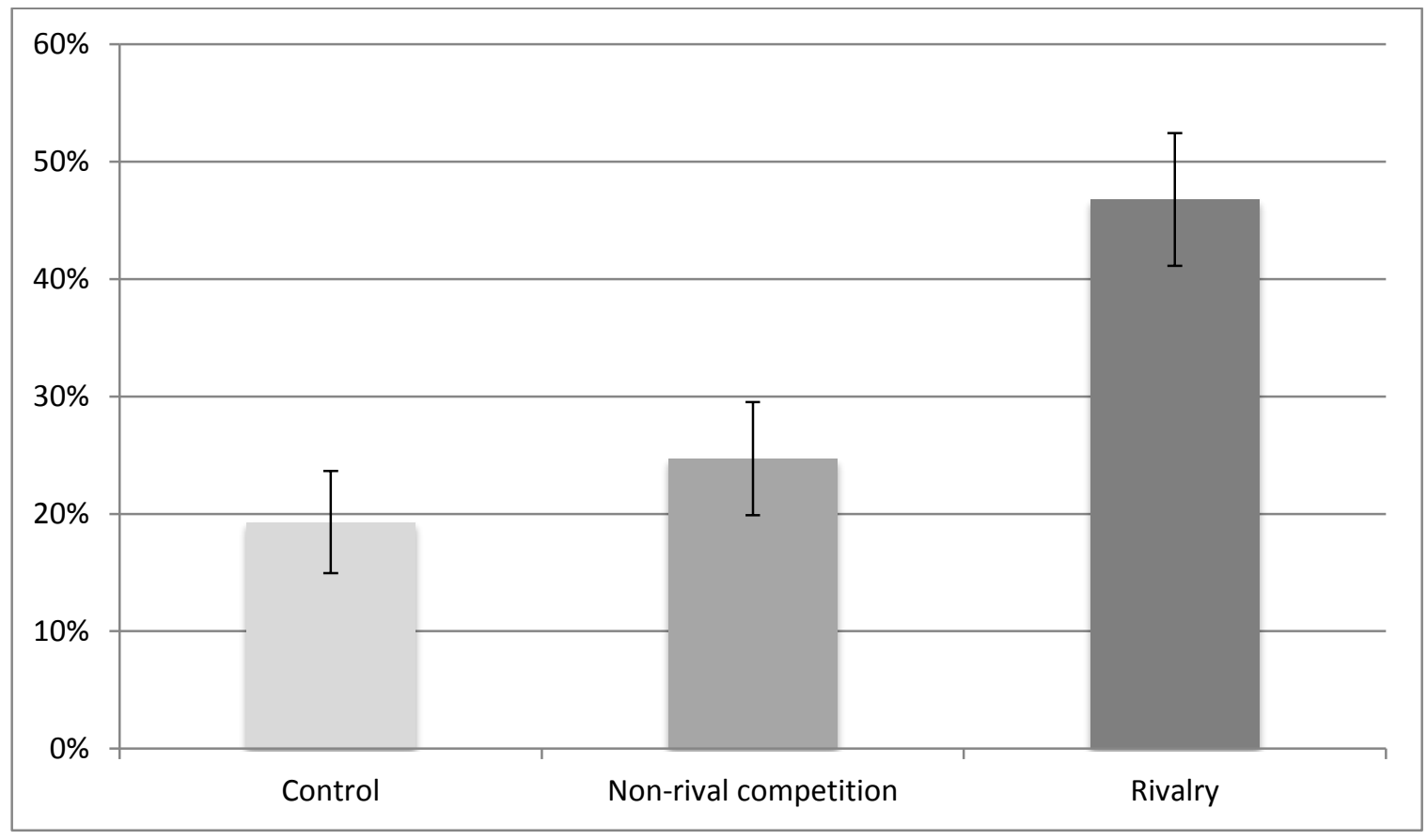

FIGURE 2

Theoretical model

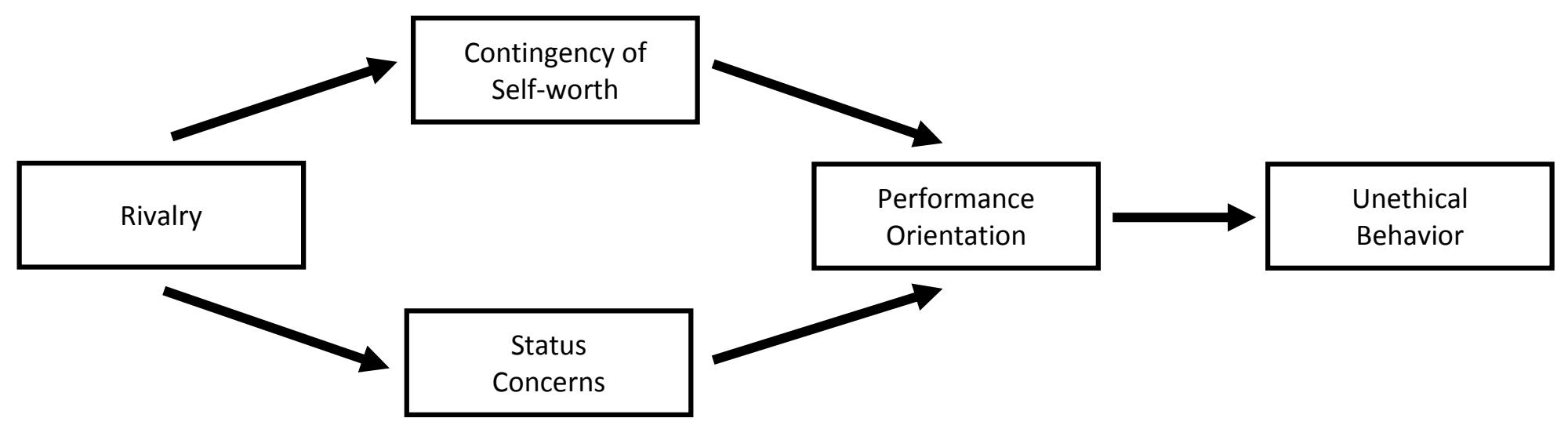


Gavin J. Kilduff (gkilduff@stern.nyu.edu) is an associate professor in the Management and Organizations department at the Stern School of Business at New York University. He received his Ph.D. from the University of California, Berkeley. His research focuses on competition and rivalry, status dynamics and hierarchy, and the impact of relationships within competitive and mixed-motive settings, such as negotiations.

Adam D. Galinsky (adamgalinsky@gsb.columbia.edu) is the Vikram S. Pandit Professor of Business and chair of the Management Division at the Columbia Business School. He received his Ph.D. from Princeton University. His research and teaching focus on leadership, power, negotiations, decision-making, diversity, and ethics.

Edoardo Gallo (edo@econ.cam.ac.uk) is a University Lecturer in the Faculty of Economics at the University of Cambridge and an Official Fellow at Queens' College. He received his D.Phil in economics from the University of Oxford. His research interests are experimental economics, networks, and behavioral economics.

J James Reade (j.j.reade@ reading.ac.uk) is a lecturer in economics at the University of Reading. He received his D.Phil in economics from the University of Oxford. His research interests are applied econometrics, with a particular interest in applications to sport, political elections and betting. 